\title{
Priority Setting in HIV, Tuberculosis, and Malaria - New Cost-Effectiveness Results From WHO-CHOICE
}

\author{
Ambinintsoa H. Ralaidovy ${ }^{1,2^{*}}{ }^{\mathbb{D}}$, Jeremy Addison Lauer ${ }^{1,3}{ }^{(0)}$, Carel Pretorius ${ }^{4}$, Olivier JT Briët ${ }^{5,6^{(}}$, Edith \\ Patouillard $^{1 \mathbb{1}}$
}

\begin{abstract}
Background: This paper forms part of an update of the World Health Organization Choosing Interventions that are Cost-Effective (WHO-CHOICE) programmes. It provides an assessment of global health system performance during the first decade of the 21st century (2000-2010) with respect to allocative efficiency in HIV, tuberculosis (TB) and malaria control, thereby shining a spotlight on programme development and scale up in these Millennium Development Goal (MDG) priority areas; and examining the cost-effectiveness of selected best-practice interventions and intervention packages commonly in use during that period.

Methods: Generalized cost-effectiveness analysis (GCEA) was used to determine the cost-effectiveness of the selected interventions. Impact modelling was performed using the OpenMalaria platform for malaria and using the Goals and TIME (TB Impact Model and Estimates) models in Spectrum for HIV and TB. All health system costs, regardless of payer, were included and reported in international dollars. Health outcomes are estimated and reported as the gain in healthy life years (HLYs) due to the specific intervention or combination. Analysis was restricted to eastern sub-Saharan Africa and Southeast Asia.

Results: At the reference year of 2010, commonly used interventions for HIV, TB and malaria were cost-effective, with cost-effectiveness ratios less than I\$ 100/HLY saved for virtually all interventions included. HIV, TB and malaria prevention and treatment interventions are highly cost-effective and can be implemented through a phased approach to full coverage to achieve maximum health benefits and contribute to the progressive elimination of these diseases. Conclusion: During the first decade of the 21st century (2000-2010), the global community has done well overall for HIV, TB, and malaria programmes as regards both economic efficiency and programmatic selection criteria. The role of international assistance, financial and technical, arguably was critical to these successes. As the global community now tackles the challenge of universal health coverage, this analysis can reinforce commitment to Sustainable Development Goal targets but also the importance of continued focus on these critical programme areas.

Keywords: Cost-Effectiveness Analysis, HIV, Tuberculosis, Malaria, Priority Setting, Universal Health Coverage Copyright: @ 2021 The Author(s); Published by Kerman University of Medical Sciences. This is an open-access article distributed under the terms of the Creative Commons Attribution License (https://creativecommons.org/licenses/ by/4.0), which permits unrestricted use, distribution, and reproduction in any medium, provided the original work is properly cited.

Citation: Ralaidovy AH, Lauer JA, Pretorius C, Briët OJ, Patouillard E. Priority setting in HIV, tuberculosis, and malaria - New cost-effectiveness results from WHO-CHOICE. Int J Health Policy Manag. 2021;10(11):678-696. doi:10.34172/ijhpm.2020.251
\end{abstract}

Article History:

Received: 21 December 2019

Accepted: 7 December 2020 ePublished: 3 January 2021

View Video Summary

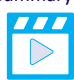

*Correspondence to:

Ambinintsoa H. Ralaidovy Email: ralaidovya@who.int

\section{Key Messages}

Implications for policy makers

- $\quad$ Country level: Continue to scale up comprehensive HIV, tuberculosis (TB), and malaria programmes.

- $\quad$ Global level: Continue to provide technical and donor assistance for HIV, TB, and malaria programmes.

- $\quad$ Both: Generalize these practices to the rest of the health system.

Implications for the public

Although more needs to be done, coverage levels are higher in HIV, tuberculosis (TB) and malaria than for other conditions in the regions studied; moreover, overall and on average the right interventions are being implemented. Yet this is not a cause for complacency. Without continued effort, regression to lower levels of epidemic control is inevitable and in some cases is already being witnessed. International collective action, in conjunction with institutions committed to strengthening domestic actors, has made a convincing case as a global public good for HIV, TB and malaria control, demonstrating that international development assistance for health can be transformative when combined with appropriate country support in the form of technical assistance about intervention choice and programme development. 


\section{Background}

The Sustainable Development Goals address universal health coverage in target 3.8. ${ }^{1,2}$ Priority setting in the context of universal health coverage emphasizes three values: improving population health, ensuring equity in access to and quality of services and avoiding impoverishment or underutilization of services as a result of out-of-pocket expenditures. ${ }^{3,4}$ Although health impact is considered to be the defining purpose of the health system, allocative efficiency can be measured with respect to any one of these values, or with respect to all three together, for example using extended cost-effectiveness analysis.

Here, we adopt generalized cost-effectiveness analysis (GCEA), an approach used by the World Health Organization's (WHO's) programme Choosing Interventions that are CostEffective (CHOICE), which has been a global leader in cost-effectiveness analysis in global health since 1998. The GCEA approach has the principal advantage of allowing for critical analysis of the package of currently implemented interventions, along with those that may be additionally considered under scaling-up scenarios.

We propose to provide a quantitative assessment of allocative efficiency within three critical diseases areas during the first decade of this century. This analysis provides a retrospective evaluation of programme development and scale up during this period. HIV, tuberculosis (TB), and malaria are of interest not only because of their prominence in the Millennium Development Goals (MDGs) but also because of the creation of The Global Fund to Fight AIDS, Tuberculosis and Malaria (The Global Fund), which contributed to an unprecedented increase in funding for combatting these infectious diseases.

This paper forms part of an update of the WHO-CHOICE programme and its previous stand-alone analyses of the costeffectiveness of interventions to combat HIV, TB, or malaria..$^{5-7}$ As in previous work, we focus here on two economically and epidemiologically diverse regions: eastern sub-Saharan Africa and Southeast Asia ${ }^{8}$ in order to have examples of the indicative cost-effectiveness of a common technology set in diverse settings. We stress the word "indicative," since the analysis is regional and has not been contextualized to particular country settings, as would be done for example for national and subnational decision-making, programme development and priority setting. Rather, we examine how implementation at a macro scale performed relative to global knowledge about best practice during the period 2000-2010.

Given that Plasmodium falciparum is the most prevalent malaria parasite in the WHO African Region and that most (56\%) cases of Plasmodium vivax malaria occur in the WHO South-East Asia Region, ${ }^{9}$ we focus our analysis on $P$. falciparum malaria, HIV and TB for the eastern sub-Saharan Africa region, and on P. vivax malaria, HIV and TB for the South-East Asia region. Finally, in light of the Phase III trials of RTS,S vaccine conducted from 2009 to 2014, we also ask how overall performance would have been changed by the addition of RTS,S vaccine to malaria control programmes.

Methods

The methods and rationale of GCEA used by WHO-CHOICE have been published elsewhere. ${ }^{10,11}$ The principal advantage of GCEA is that it allows for an analysis of the package of currently implemented interventions, along with those that may be considered under alternative or scaling-up scenarios. The cost-effectiveness of interventions is examined first individually against a "null" scenario, a counterfactual scenario in which the effects of all currently implemented interventions are removed, and second as packages of interventions defined as combinations of the most costeffective individual interventions. To allow for comparison and integration of results in a sectoral analysis, common methods and assumptions are applied for HIV, TB, and malaria. Health outcomes are measured and reported as the gain in healthy life years (HLYs) due to a specific intervention or combination thereof. For the calculation of HLYs, disease weights were obtained from the Global Burden of Disease study, 2010.12 For costing, all market-traded health system inputs are costed, regardless of payer (ie, programme costs, service delivery of the intervention, drugs and expendables). As is common, programmes are considered to be implemented for 100-year lifetime horizon using a population model that calculates duration-dependent life-table effects such as healthy life expectancy. A 3\% per annum discount rate is applied to costs in all scenarios. HLY are reported both undiscounted and with a $3 \%$ per annum discount rate.

The cost-effectiveness of disease-specific sets of regional counterfactual scenarios is assessed against a null comparator (no intervention), along with individual and combined interventions, including seven scenarios for $P$. vivax malaria (Table 1), 14 for P. falciparum malaria (Table 2), 12 for HIV (Table 3) and 10 for TB (Table 4). The effects and costs of current (ie, actual) practice were also assessed relative to this baseline. Interventions are analysed at 50\%, 80\% and 95\% coverages; details for the current scenarios can be found in Tables 5, 6, 7 and 8 .

The list of interventions is not exhaustive and excluding an intervention does not imply that it is cost ineffective. The term "current" as used here refers to an intervention that represents the average combination of interventions used in typical countries in the relevant geographical area at year 2010. Some of these interventions, however, do not reflect the recommendations of WHO anymore, and up-to-date WHO recommendations can be found in Table 9. Thus, our results are intended to be indicative of average implementation performance relative to global knowledge of best practices at the time, rather than as prescriptive packages intended for countries to implement now. As noted, our principal objective here is to assess and evaluate retrospectively programmatic performance in HIV, TB and malaria control during the first decade of the 21 st century. In addition, in the case of malaria, we also assess the potential cost-effectiveness of the RTS,S vaccine in the context of our GCEA framework.

An expansion path shows the steps in programme expansion that a hypothetical decision-maker could follow when maximizing health. However, in constructing such an expansion path, even when maximization of population health is the goal it is presumably important to consider other factors too, such as the investment by the health system in a set of fixed 
Table 1. Interventions Included in the Analysis for Plasmodium vivax Malaria

\begin{tabular}{lll}
\hline$\#$ & Scenario Name & Description \\
\hline 1 & CMS & Management of severe cases \\
2 & ITN & Insecticide-treated bed nets \\
3 & CMS_ITN & Management of severe cases + Insecticide-treated bed nets \\
4 & CMU_CMS & Management of suspected uncomplicated cases + Management of severe cases \\
5 & CMU_CMS_ITN & Management of suspected uncomplicated cases + Management of severe cases + Insecticide-treated bed nets \\
6 & CMUPQX_CMS & As \#4 with primaquine only given to non-G6PDd males \\
7 & CMUPQX_CMS_ITN & As \#5 with primaquine only given to non-G6PDd males \\
\hline
\end{tabular}

Abbreviation: G6PDd, glucose-6-phosphate dehydrogenase (G6PD) deficient.

* PQX: G6PDd testing in males, non-deficient males receive primaquine, and all others (G6PDd males and all females) do not receive primaquine.

Table 2. Interventions Included in the Analysis for Plasmodium falciparum Malaria

\begin{tabular}{|c|c|c|}
\hline \# & Scenario Name & Description \\
\hline 1 & CMS & Management of severe cases \\
\hline 2 & ITN & Insecticide-treated bed nets \\
\hline 3 & CMS_ITN & Management of severe cases + Insecticide-treated bed nets \\
\hline 4 & CMU_CMS & Management of suspected uncomplicated cases + Management of severe cases \\
\hline 5 & CMU_CMS_ITN & Management of suspected uncomplicated cases + Management of severe cases + Insecticide-treated bed nets \\
\hline 6 & CMS_RTSS & Management of severe cases + Malaria vaccine with RTS, S \\
\hline 7 & ITN_RTSS & Insecticide-treated bed nets + Malaria vaccine with RTS, S \\
\hline 8 & CMS_ITN_RTSS & Management of severe cases + Insecticide treated bed nets + Malaria vaccine with RTS,S \\
\hline 9 & CMU_CMS_RTSS & Management of suspected uncomplicated cases + Management of severe cases + Malaria vaccine with RTS, S \\
\hline 10 & CMU_CMS_ITN_RTSS & $\begin{array}{l}\text { Management of suspected uncomplicated cases + Management of severe cases + Insecticide treated bed nets + Malaria } \\
\text { vaccine with RTS,S }\end{array}$ \\
\hline 11 & CMU_D*_CMS & As \#4, but treatment seeking fever cases RDT tested \\
\hline 12 & CMU_D*_CMS_ITN & As \#5, but treatment seeking fever cases RDT tested \\
\hline 14 & CMU_D*_CMS_ITN_RTSS & As \#10, but treatment seeking fever cases RDT tested \\
\hline
\end{tabular}

Abbreviation: RDT, Malaria rapid diagnostic test.

*D: Diagnostics

Table 3. Interventions Included in the Analysis for HIV

\begin{tabular}{lll}
\hline$\#$ & Scenario Name & Description \\
\hline 1 & FSW & Female sex workers and clients \\
2 & PWID & People who inject drugs community outreach and peer education \\
3 & MMCO & Mass media communication designed to increase demand and improve use of condoms, and condom provision \\
4 & MSM & Interventions targeting men who have sex with men \\
5 & VMMC & Voluntary medical male circumcision \\
6 & YFIs & Youth focused interventions \\
7 & ART3 & HIV testing services + Antiretroviral therapy for all HIV positive adults with CD4 <350, all HIV positive children $\leq 2$ years, children $>2$ \\
8 & ART5 & HIV testing services + Antiretroviral therapy for all HIV positive adults with CD4 <500, all HIV positive children $\leq 2$ years, children>2 \\
9 & TasP & yrs with CD4 <500, pregnant women Option B+* \\
10 & CB1 & ART testing services + Antiretroviral therapy treatment as prevention for all HIV positive adults, children and PMTCT Option B+ \\
11 & CB2 & ART5 + MMCO + FSW +PWID + MSM +YFI + Management of sexually transmitted infections + VMMC \\
12 & CB3 & TASP + MMCO + FSW +PWID + MSM +YFI + Management of sexually transmitted infections + VMMC
\end{tabular}

Abbreviation: PMTCT, prevention of mother-to-child transmission.

*Pregnant women Option B+: lifelong antiretroviral therapy treatment given to HIV positive pregnant women regardless of CD4 count or WHO clinical stage. ${ }^{37}$

assets such as equipment, facilities and human resources that cannot be readily redeployed to alternative uses. We therefore present two expansion paths, one, a health-maximizing expansion path that has no constraints apart from the costeffectiveness of interventions, and, two, a programmatic expansion path that respects the fact that health system resources represent asset-specific investments that cannot be easily redeployed. In other words, while an "expansion path" reflects an indicative optimal path for the expansion of health services, more broadly speaking the concept of optimal also 
Table 4. Interventions Included in the Analysis for TB

\begin{tabular}{lll}
\hline$\#$ & Scenario Name & Description \\
\hline 1 & B2 & Treatment (FLD + SLD) + Detection (Xpert + X-ray + Culture) + Drug susceptibility testing \\
2 & B2_AX & Treatment (FLD + SLD) + Detection (Xpert + X-ray + Culture) + Drug susceptibility testing + ART prioritization for TB cases \\
3 & B2_AX_PX_PXC & $\begin{array}{l}\text { Treatment (FLD + SLD) + Detection (Xpert + X-ray + Culture) + Drug susceptibility testing + ART prioritization for TB cases + } \\
\text { Preventive therapy + Preventive therapy for children }\end{array}$ \\
4 & B2_PX & Treatment (FLD + SLD) + Detection (Xpert + X-ray + Culture) + Drug susceptibility testing + Preventive therapy \\
5 & B2_PXC & Treatment (FLD + SLD) + Detection (Xpert + X-ray + Culture) + Drug susceptibility testing + Preventive therapy for children \\
6 & B1 & Treatment (FLD + SLD) + Detection (Smear + X-ray + Culture) + Drug susceptibility testing \\
7 & B1_AX & Treatment (FLD + SLD) + Detection (Smear + X-ray + Culture) + Drug susceptibility testing + ART prioritization for TB cases \\
8 & B1_AX_PX_PXC & $\begin{array}{l}\text { Treatment (FLD + SLD) + Detection (Smear + X-ray + Culture) + Drug susceptibility testing + ART prioritization for TB cases + } \\
\text { Preventive therapy + Preventive therapy for children }\end{array}$ \\
9 & B1_PX & Treatment (FLD + SLD) + Detection (Smear + X-ray + Culture) + Drug susceptibility testing + Preventive therapy \\
10 & B1_PXC & Treatment (FLD + SLD) + Detection (Smear + X-ray + Culture) + Drug susceptibility testing + Preventive therapy for children \\
\hline
\end{tabular}

Abbreviations: ART, antiretroviral therapy; FLD, first line drugs, SLD, second line drugs; TB, tuberculosis.

Table 5. Population in Need and Current Coverage for Plasmodium vivax Malaria

\begin{tabular}{|c|c|c|c|}
\hline Interventions & Population in Need & Current Coverage (\%) & References \\
\hline $\mathrm{CMU}$ & \multirow{3}{*}{$\begin{array}{l}\text { All - age population, men and women living in malaria } \\
\text { endemic areas }\end{array}$} & 52 & \multirow{3}{*}{$20,21,25$} \\
\hline ITN & & 21 & \\
\hline CMS & & 48 & \\
\hline
\end{tabular}

Abbreviations: ITN, insecticide-treated net; CMS, management of severe cases; CMU, management of suspected uncomplicated cases.

Table 6. Population in Need and Current Coverage for Plasmodium falciparum Malaria

\begin{tabular}{llc}
\hline Interventions & Population in Need & Current Coverage (\%) \\
\hline CMU & All - age population, men and women living in malaria & 40 \\
ITN & endemic areas & 58 \\
CMS & & $20,21,26$ \\
\hline
\end{tabular}

Abbreviations: ITN, insecticide treated net; CMS, management of severe cases; CMU, management of suspected uncomplicated cases.

includes criteria related to programme acceptability. For example, bringing a highly cost-effective intervention to full coverage in a given year only to drop it and replace it with a different intervention, requiring different fixed assets, when higher levels of funding are available the following year is a possibility that can be excluded on programmatic grounds due to the large fixed costs associated with changing asset specific investments. If such a case is suggested on costeffectiveness grounds in the health maximizing expansion path, the programmatic expansion path can be "forced" to adopt early the intervention that will ultimately be optimal at full implementation. This means that, if a particular technology appears on the expansion path at a higher level of coverage, then for the previous steps, we considered only the most cost-effective combination of interventions that also included this particular technology at the same or lower levels of coverage. This procedure allows for trade-offs between cost-effectiveness and investment in fixed assets (ie, health system strengthening) to be quantified. Finally, we note that the concept of an expansion path in either of these guises (health maximizing or programmatic) is at base only an indicative device to illustrate trade-offs potentially made by the policy-maker in the course of health system development.

These WHO-CHOICE results are provided at regional level; as further contextualization would be necessary for individual country-level implementation,,$^{13}$ so these scenarios should be considered only as estimates of actual average performance at macro level, versus the counterfactual of idealized average performance at macro level, during the period 2000-2010.

Impact Modelling

Malaria Model

Simulations for $P$. falciparum malaria and $P$. vivax malaria were performed using the OpenMalaria platform, ${ }^{14}$ an open-source $\mathrm{C}++$ program for micro-simulating malaria epidemiology and the impacts of interventions on disease burden. A WHOCHOICE population model, PopMod, ${ }^{15}$ was used to combine projected case incidence, parasite clearance and mortality data from OpenMalaria with health state valuations in order to calculate the population impact of the scenarios.

All malaria simulations were based on a scenario used earlier. ${ }^{16-18} \mathrm{~A}$ major innovation compared to that scenario ${ }^{16}$ is the inclusion of fevers with non-malarial aetiology. This scenario including non-malarial fever modelling was adapted to country-specific conditions for: seasonality of transmission, history of insecticide-treated net (ITN) use, history of case management coverage and intensity of transmission. For $P$. vivax, the prevalence of G6PD deficiency ${ }^{19}$ was also taken into account.

Management of severe cases was presumed to be constant 
Table 7. Population in Need and Current Coverage for HIV

\begin{tabular}{|c|c|c|c|c|}
\hline \multirow[b]{2}{*}{ Intervention } & \multirow[b]{2}{*}{ Population in Need } & \multicolumn{2}{|c|}{ Current Coverage (\%) } & \multirow[b]{2}{*}{ References } \\
\hline & & $\begin{array}{l}\text { Eastern Sub- } \\
\text { Saharan Africa }\end{array}$ & $\begin{array}{l}\text { Southeast } \\
\text { Asia }\end{array}$ & \\
\hline FSWs and clients & FSWs aged $15-49$ years & 31 & 67 & \multirow{9}{*}{$\begin{array}{l}38,39 \\
\text { UNGASS reports, data collected } \\
\text { for the UNAIDS global report } \\
\text { (analogous to the TB reports) } \\
\text { and data collected for the } \\
\text { Resource Needs Model exercises }\end{array}$} \\
\hline $\begin{array}{l}\text { PWID community outreach } \\
\text { and peer education }\end{array}$ & PWIDs aged $15-49$ years (male and female) & 10 & 33 & \\
\hline Mass media & Population aged $15-49$ years (male and female) & 29 & 31 & \\
\hline Condom provision & Population aged $15-49$ years (male and female) & 27 & 28 & \\
\hline MSM & MSM aged $15-49$ years & 25 & 28 & \\
\hline VMMC & Population aged $10-19$ years (male) & 70 & - & \\
\hline YFIs & $\begin{array}{l}\text { Population aged } 15-49 \text { years (male and female) and STI } \\
\text { symptomatic }\end{array}$ & 60 & 18 & \\
\hline STI management & $\begin{array}{l}\text { Population aged } 15-49 \text { years (male and female) and STI } \\
\text { symptomatic }\end{array}$ & 36 & 23 & \\
\hline HIV testing services & Population aged $15-49$ years (male and female) & 23 & 4 & \\
\hline
\end{tabular}

Abbreviations: FSWs, female sex workers; PWID, people who inject drug; MSM, Men who have sex with men; VMMC, voluntary medical male circumcision; STI, sexually transmitted infection; YFIs, youth focused interventions; UNGASS, United Nations General Assembly Special Session on Drugs; UNAIDS, the Joint United Nations Programme on HIV/AIDS; TB, tuberculosis.

Table 8. Population in Need and Current Coverage for TB

\begin{tabular}{|c|c|c|c|c|}
\hline \multirow[b]{2}{*}{ Interventions } & \multirow[b]{2}{*}{ Population in Need } & \multicolumn{2}{|c|}{ Current Coverage (\%) } & \multirow[b]{2}{*}{ References } \\
\hline & & $\begin{array}{l}\text { Eastern Sub- } \\
\text { Saharan Africa }\end{array}$ & $\begin{array}{l}\text { Southeast } \\
\text { Asia }\end{array}$ & \\
\hline Detection & & 73 & 65 & \\
\hline Screening & All age population, men and women & & & $\begin{array}{l}\text { Screening rate is a } \\
\text { fitting parameter }\end{array}$ \\
\hline Algorithm sensitivity and specificity & $\begin{array}{l}\text { TB susceptible and active TB cases, as applicable to } \\
\text { diagnostic method }\end{array}$ & & & $41-43$ \\
\hline Drug sensitivity test & Active new and previously treated TB cases & & & 46,47 \\
\hline Treatment & Active TB cases, with diagnosis and linked to care & 85 & 80 & 46,47 \\
\hline ART prioritization & HIV-positive TB cases, not on ART & 80 & 40 & 46,47 \\
\hline Preventive therapy & Ages $15+$, men and women, LTBI cases & 40 & 40 & 46,47 \\
\hline Preventive therapy for children & Ages 0-14, LTBI cases & 23 & 50 & 46,47 \\
\hline
\end{tabular}

Abbreviations: ART, antiretroviral therapy; LTBI, latent TB infection; TB, tuberculosis.

over time and across countries of the same region, and the probability of treatment per five-day time step was assumed to be $48 \%{ }^{20,21}$ The per-capita rates of malaria cases and deaths from OpenMalaria were scaled to WHO case incidence estimates per country in 2010.22 Similarly, the number of treatments (with or without diagnostic tests), and the number of diagnostic tests, at a given coverage level were also scaled to the WHO estimates of cases.

\section{Interventions Against Malaria}

ITNs. Net distribution was modelled on an annual basis and their effect was hypothesised to last one year (modelled with a step-wise attrition function) in order to prevent periodic effects that complicates the analysis without adding information about intervention efficiency. During the year, no chemical or physical decay was modelled. Costing of nets, however, was done on the basis of actual estimates of useful life. ${ }^{23}$ For $P$. falciparum malaria, ITN efficacy was based on Anopheles gambiae, ${ }^{16-18}$ while for $P$. vivax malaria, it was based on Anopheles epiroticus. ${ }^{16-18}$
Case management and diagnostic testing. Without testing, fevers without parasites, fevers with incidental parasites (ie, fevers that occur in people that are not caused by the malaria infection), and malarial fevers (ie, fevers caused by the malaria infection) have an equal probability of being treated with an antimalarial. With testing, fevers without parasites are not treated. Without G6PD testing, all P. vivax positive patients except pregnant women should receive primaquine. With G6PD testing, a status of non-eligibility for primaquine (either due to G6PD deficiency, or due to policy regarding primaquine treatment) was assigned at birth with a pre-set probability dependent on the proportion of hemizygous men in the population.

RTS,S. Malaria vaccine was modelled as previously done by Swiss TPH for the Malaria Vaccine Initiative. ${ }^{24}$ While this vaccine is not yet recommended for wide deployment by WHO, it is a potential new intervention that was included in this study on account of the persistent policy interest it attracts. 
Table 9. WHO Recommended Interventions

\begin{tabular}{|c|c|c|c|}
\hline Disease & Category & Intervention & References \\
\hline \multirow{22}{*}{ HIV } & \multirow{8}{*}{ Prevention } & Male and female condoms and lubricants & 48 \\
\hline & & Harm reduction for people who inject drugs & 48,49 \\
\hline & & $\begin{array}{l}\text { Antiretroviral-based prevention: pre-exposure prophylaxis, post-exposure prophylaxis, prevention of } \\
\text { mother-to child transmission, antiretroviral therapy that achieves viral suppression }\end{array}$ & 48,50 \\
\hline & & Prevention of HIV infection in infants & 48 \\
\hline & & VMMC & 48 \\
\hline & & Injection and blood safety & 48 \\
\hline & & $\begin{array}{l}\text { Behaviour change interventions (specific to particular population groups including adolescent } \\
\text { girls and young women) }\end{array}$ & 48 \\
\hline & & Prevention and management of gender-based and sexual violence & 48 \\
\hline & Testing & HIV testing & $48,51,52$ \\
\hline & \multirow{6}{*}{ Treatment and Care } & Expand antiretroviral therapy coverage & 48,50 \\
\hline & & Prevent and manage HIV and TB coinfection & 48 \\
\hline & & Prevent and manage HIV and viral hepatitis coinfection & 48 \\
\hline & & Address other HIV coinfections & 48 \\
\hline & & Prevent and manage HIV drug resistance & 48 \\
\hline & & Provide person-centred chronic care for people living with HIV & 48 \\
\hline & \multirow{7}{*}{$\begin{array}{l}\text { Comprehensive package } \\
\text { for key populations } \\
\text { (MSM, PWIDs, people in } \\
\text { prisons and other closed } \\
\text { settings, sex workers and } \\
\text { transgender people) }\end{array}$} & Comprehensive condom and lubricant programming & \multirow{7}{*}{49} \\
\hline & & $\begin{array}{l}\text { Harm reduction interventions for substance use (in particular needle and syringe programmes and, } \\
\text { opioid substitution therapy and naloxone distribution) }\end{array}$ & \\
\hline & & Behavioural interventions & \\
\hline & & HIV testing and counselling & \\
\hline & & HIV treatment and care & \\
\hline & & Prevention and management of co-infections and other co-morbidities & \\
\hline & & Sexual and reproductive health interventions & \\
\hline \multirow{12}{*}{ TB } & \multirow{3}{*}{ Prevention } & Treatment of LTBI & \multirow{3}{*}{ 53-55 } \\
\hline & & Prevention of transmission of Mycobacterium tuberculosis through infection prevention and control & \\
\hline & & Vaccination of children with the BCG vaccine & \\
\hline & \multirow{7}{*}{ Detection } & $\begin{array}{l}\text { Early diagnosis of TB including universal drug susceptibility testing, and systematic screening of } \\
\text { contacts and high risk groups }\end{array}$ & 53 \\
\hline & & Rapid molecular test: Xpert ${ }^{\circledR}$ MTB/RIF assay (Cepheid, USA) & 55 \\
\hline & & Sputum smear microscopy & 55 \\
\hline & & Culture-based methods & 55 \\
\hline & & First-line LPAs & 55 \\
\hline & & Second-line LPA & 55 \\
\hline & & $\begin{array}{l}\text { DST by phenotypic or genotypic methods should be done for all persons with bacteriologically } \\
\text { confirmed TB }\end{array}$ & 53 \\
\hline & \multirow{2}{*}{ Treatment and Care } & Treatment of all people with TB including drug resistant TB, and patient support & $53,55,56$ \\
\hline & & Collaborative TB/HIV activities, and management of co-morbidities & $53,55,57$ \\
\hline \multirow{8}{*}{ Malaria } & \multirow{4}{*}{$\begin{array}{l}\text { Prevention (core } \\
\text { intervention) }\end{array}$} & ITNs/LLINs or IRS & 58 \\
\hline & & IPTp & 59,60 \\
\hline & & IPTi & 61 \\
\hline & & SMC & 62 \\
\hline & Testing & RDTs or microscopy & \multirow{4}{*}{63} \\
\hline & \multirow{3}{*}{ Treatment } & Treatment of blood-stage infection ( for $P$. falciparum and $P$. vivax) & \\
\hline & & $\begin{array}{l}\text { Treatment of liver-stage infection (not applicable for } P \text {. falciparum and includes G6PD testing for } \\
\text { confirmed cases of } P \text {. vivax) }\end{array}$ & \\
\hline & & Treatment of severe malaria & \\
\hline
\end{tabular}

Abbreviations: WHO, World Health Organization; VMMC, voluntary medical male circumcision; TB, tuberculosis; PWID, people who inject drug; MSM, Men who have sex with men; LTBI, latent TB infection; BCG, Bacillus Calmette-Guérin; LPA, line probe assays; DST, drug-susceptibility testing; ITNs, insecticide-treated nets; LLINs, long lasting insecticidal nets; IRS, indoor residual spraying; IPTp, Intermittent preventive treatment of malaria in pregnancy; IPTi, Intermittent preventive treatment of infants; SMC, seasonal malaria chemoprevention; RDTs, rapid diagnostic tests. 


\section{HIV Model}

Simulations for HIV were performed with the Goals model, a dynamic compartmental model developed in the Spectrum suite of models. ${ }^{27-32}$ The Goals model is widely-used to produce projections of epidemic trends as well as projections of the impact of interventions. It has been used in many regions, particularly in the Southern and Eastern African region, to study the cost and impact of national and other HIV strategies.

Goals simulates transmission of HIV and its morbidity and mortality consequences for adult populations aged 15-49 years, which are structured into five risk categories: stable couples (men and women reporting a single partner in the last year), multiple partners (men and women with more than one partner in the last year), female sex workers (FSW) and clients, men who have sex with men (MSM), and people who inject drugs (PWID). These groups are based on risk stratifications available in publicly available data sources, such as Demographic and Health Surveys and AIDS Indicator Surveys, as well in behavioural surveys. HIV transmission in Goals is explicitly calculated from behavioural (eg, age at first sex, number of sexual partners and number of sex acts per sexual partner) and biomedical (eg, antiretroviral therapy [ART], condom use and voluntary medical male circumcision [VMMC]) characteristics.

Goals is directly linked to the AIDS Impact Model (AIM) module in Spectrum, which is used annually to produce national HIV burden estimates towards the Global AIDS report. ${ }^{28,29}$ Goals uses the HIV progression structure in AIM, in which HIV progression is captured through movement between CD4 categories, which form the basis of ART eligibility criteria, ART initiation and ART coverage levels and is also the basis of mortality patterns.

AIM also estimates the effects of programs preventing mother-to-child transmission. ${ }^{33,34}$ AIM further calculates corresponding epidemic patterns for children (0-14 years) and models HIV progression for adults above 49 years.

\section{Interventions Against HIV}

The impact of behavioural interventions for HIV is represented by an impact matrix which summarizes the impact of key behavioural interventions (eg, community mobilization, mass media campaigns, condom distribution programs, outreach to key populations) with respect to the reduction of condom non-use, reduction of number of partners, and increase in age at first sex for the populations outlined above, based on metaanalyses of research studies. ${ }^{33-36}$

In addition to these behavioural factors, HIV transmission risk further depends on biomedical factors including ART use, VMMC, the prevalence of other sexually transmitted infections (STIs) and the use of pre-exposure prophylaxis.

Interventions in Goals can change any of these factors, and thereby affect HIV transmission risk and the future course of the epidemic.

To apply intervention structure of the Goals model to our CHOICE scenarios, we constructed three ART scenarios in which eligibility for ART is progressively relaxed. In the first scenario ART is provided to all children 2 years and younger, to all other children under the age of 15 , to all adults ( 15 years and older) with CD4 count below 350 cells/uL and Option $\mathrm{B}+$ (ART continued after a pregnancy during which ART is initiated) is followed in the PMTCT (prevention of motherto-child transmission) program. The second scenario is the same except that a CD 4 count below 500 cells/uL replaces CD4 350 cells/uL in the definition of the first scenario. In the third scenario CD4 count is removed as an eligibility criterion and ART is applied as prevention (the so-called TasP strategy). All these strategies assume HIV testing services as part of ART enrolment process. Testing is an entry point and it matters who gets testing services since impact depends on it.

The list of interventions is extended through VMMC, STI treatment, behavioural interventions (mass media, condom distribution and youth-based programs) as well as outreach programs to high-risk groups (FSW and their clients, PWID and MSM outreach). Three combination scenarios are defined by adding these interventions to the three ART scenarios.

\section{Tuberculosis Model}

Simulations for TB were performed with the Impact component of the TB Impact Model and Estimates (TIME) model, a dynamic compartmental TB model developed in the open-source Spectrum suite of models. ${ }^{27,40}$

TIME is used by TB policy-makers and national TB programmes to develop strategic responses and strategies for $\mathrm{TB}$ and to produce projections that inform funding applications. The model has been used in most TB settings, including in countries where TB is driven by HIV, in weak health systems, in countries with high MDR-burden and in countries where TB programs depend on a high level of private-sector involvement. The Estimates component of TIME was used by the Global TB Programme to produce estimates for HIV-TB burden towards the Global TB Report.

The TIME model reflects key aspects of the natural history of TB including primary and latent infection, re-infection and re-activation of latent TB. Smear positivity, negativity and smear conversion is explicitly handled. TIME also accounts for the characteristics of paediatric TB, treatment history and drug resistance. It has additional structure for HIV/ART which mimics the structure of the Spectrum AIM module to use its HIV programmatic data directly. TIME includes two generic TB strains: susceptible and resistant to multi-drug treatment. Resistance can be acquired during treatment upon transmission, at rates that distinguish it from the susceptible TB type in the model.

\section{Interventions Against Tuberculosis}

A description of the TIME model and its parametrization can be found in the technical appendix of Houben et al. ${ }^{40}$ Interventions in TIME are structured according to a general care-and-control cascade for TB, which is further structured by HIV and MDR status as relevant. The cascade starts with a screening rate which is defined for smear-positive cases, and relative screening rates are specified for smear-negative and TB susceptible cases. Diagnosis of TB is defined by sensitivity 
and specificity values which are used to characterise the most widely-used and WHO-recommended diagnostic tools in diagnostic pathways for TB. Estimates of diagnostic sensitivity and specificity used in TIME are based on those discussed in. ${ }^{41-43}$

Following screening and diagnosis, cases are linked to care at a specified acquisition rate and then treated at a specified success rate. The model does not explicitly model a delay between diagnosis and treatment. Coverage, sensitivity and specificity of drug-susceptibility testing (DST) for treatment naive and previously treated cases are specified. These inputs characterize MDR diagnosis and notification, including notification of non-MDR cases as MDR due to non-perfect specificity of DST.

The model has a detailed structure for active case finding and household-based contact tracing for children and adults as well as subsequent links to preventive therapy for cases identified with latent TB on the basis of a detailed testing algorithm. Prioritized access to ART for HIV-positive TB cases is explicitly linked to ART enrolment numbers from the Spectrum AIM model.

To use the intervention structure of the TIME model in our CHOICE analysis, we constructed a basic care-and-control scenario which comprise screening (of all populations, including smear, HIV and MDR-status), detection (including DST to find MDR among new and retreatment cases) and treatment for non-MDR and MDR case (including cases that are false diagnosed due to non-perfect specificity). The different components of the basic care cascade cannot be individually studied, but rather only as packages.

The basic package, however, has two variations. One represents a traditional diagnostic algorithm of symptomatic screening, followed with smear microscopy or clinical diagnosis and culture for MDR diagnosis. A second scenario represents a recommended design for future diagnostic algorithms which are projected to change to an increasing and dominant use of X-ray for screening and rapid molecular tests such GeneXpert for diagnosis of non-MDR and detection of rifampicin resistance, and by assumption diagnosis of the general MDR strain in our model.

Core interventions recommended in the End TB Strategy ${ }^{44}$ and the Global Plan to End TB 2016-2020 $0^{45}$ are added to the basic care-and-control cascade. First is preventive therapy for HIV-positive TB cases not on ART and on ART with latent TB infection (LTBI). Then preventive therapy for children ages (0-14) with LTBI found in the context of house-hold screening of index cases. Finally, we added ART prioritization for notified HIV-positive TB cases, irrespective of CD4 count.

This overall intervention structure is kept general and does not address specific activities or implementation approaches that are necessary to implement the package. In different TB contexts screening rates might be increased through active case finding and enhanced passive case finding in specific groups at high risk of TB infection (eg, diabetics, prisoners, miners, and so on). Community health workers are often employed to improve high treatment success. We made no assumptions regarding these types of underlying activities that are required to achieve the coverage levels of the intervention packages studied.

We also made no assumption regarding the future trend of the number of tests that will be needed to find one case, and kept the value fixed at 10, which is considered an average value. Generally, it is expected that this value will increase as more aggressive screening policies are adopted by national $\mathrm{TB}$ programmes. These are considered too context specific to study here.

\section{Interventions Costs}

We used a framework developed for WHO-CHOICE for costing interventions. This framework includes patient-level delivery costs, programme costs, and other health system costs, regardless of payer (eg, private or public). We developed the costing estimates under the assumption that health system capacity is available to support the interventions. The quantities of resources assumed used at patient level were based on adherence to WHO treatment guidelines. Programme costs were calculated in a standardized way, as reported in. ${ }^{64}$ Costs were discounted at $3 \%$ per annum, and capital expenses annualized over the lifetime of the good. All prices are reported in 2010 international dollars. Costing

Table 10. Intervention Costing Assumptions for Plasmodium vivax Malaria

\begin{tabular}{ll}
$\begin{array}{l}\text { Patient Costs (*Regional Average Unit Costs Per Person Per Year - I\$ } \\
\text { 2010) }\end{array}$ \\
\hline Management of uncomplicated cases & 6.33 \\
Management of severe cases & 173.91 \\
ITNs & 5.47 \\
\hline
\end{tabular}

Abbreviation: ITNs, insecticide-treated nets.

* Prices of drugs from various sources: MSH database: http://erc.msh. org/, UNICEF LLIN data (2014). UNICEF supply catalogue (2012) and WHOCHOICE price database. Unit costs include logistics, wastage, and freight and insurance (when relevant). ITN's unit cost is the average cost per net delivered. Consumables required for management for severe cases include those needed for pre-referral treatment, hospital treatment, and postdischarge follow-up.

Table 11. Intervention Costing Assumptions for Plasmodium falciparum Malaria Patient Costs (*Regional Average Unit Costs Per Person Per Year - I\$ 2010)

\begin{tabular}{ll}
\hline Management of suspected uncomplicated cases & 2.06 \\
$\begin{array}{l}\text { Management of suspected uncomplicated cases } \\
\text { (without diagnosis) }\end{array}$ & 1.41 \\
Management of severe cases & 57.55 \\
ITNs & 5.47 \\
RTS,S & 7.25 \\
\hline
\end{tabular}

Abbreviation: ITNs, insecticide-treated nets.

* Prices of drugs from various sources: MSH database: http://erc.msh. org/, UNICEF LLIN data (2014). UNICEF supply catalogue (2012), WHO/ IVB/06.15 $5^{65}$ and WHO-CHOICE price database. Unit costs include logistics, wastage, and freight and insurance. ITN's unit cost is the average cost per net delivered. RTS,S's unit cost is the average cost per dose delivered. Consumables required for management for severe cases include those needed for pre-referral treatment, hospital treatment, and post-discharge follow-up.discharge follow-up. 
Table 12. Intervention Costing Assumptions for HIV

\begin{tabular}{|c|c|c|}
\hline $\begin{array}{l}\text { Patient Costs (I\$ 2010) (regional Average } \\
\text { Unit Costs Per Person Reached Per Year) }\end{array}$ & $\begin{array}{l}\text { Eastern Sub- } \\
\text { Saharan Africa }\end{array}$ & $\begin{array}{l}\text { Southeast } \\
\text { Asia }\end{array}$ \\
\hline Youth-focused interventions & 12.22 & 13.97 \\
\hline FSWs and clients & 8.78 & 28.29 \\
\hline MSM & 9.30 & 32.82 \\
\hline $\begin{array}{l}\text { IDU community outreach and peer } \\
\text { education }\end{array}$ & 6.60 & 21.80 \\
\hline Condom provision & 0.50 & 0.15 \\
\hline STI management & 9.19 & 34.07 \\
\hline Voluntary counselling and testing & 12.48 & 31.73 \\
\hline VMMC & 56.26 & 58.11 \\
\hline PMTCT screening & 4.43 & 3.74 \\
\hline PMTCT ARVs & 597.23 & 986.63 \\
\hline Mass media & 0.95 & 0.95 \\
\hline Service Delivery & 100.77 & 54.95 \\
\hline \multicolumn{3}{|l|}{ ART } \\
\hline Labs & 33.23 & 259.50 \\
\hline ARVs - 1st line & 130.35 & 128.65 \\
\hline ARVs - 2nd line & 308.34 & 518.33 \\
\hline Pre-ART & 118.74 & 233.93 \\
\hline Non-ART care and prophylaxis & 302.70 & 302.70 \\
\hline Palliative care & 236.14 & 236.14 \\
\hline
\end{tabular}

Abbreviations: FSWs, female sex workers; MSM, Men who have sex with men; IDU, injecting drug users; STI, sexually transmitted infection; VMMC, voluntary medical male circumcision; PMTCT, prevention of mother-to-child transmission; ARVs, antiretroviral; ART, Antiretroviral therapy.

details for each programme area can be found in Tables 10, 11, 12 and 13.

Results

Tables 14-19 show the costs, effects and cost-effectiveness of the different interventions. These tables present only the most cost-effective interventions on the two expansion paths for each of the disease areas. Interventions that are "dominated" ie, are more costly or less effective, are presented in Supplementary file 1. Figures 1-6 show the steps reflecting the expansion paths that a hypothetical decision-maker could follow for the expansion of services with increasing levels of budget. Both the health-maximizing and the programmatic expansion path are presented. However, we consider the programmatic expansion path for the main results, while also discussing where relevant the implications of the health maximizing expansion path. A zoom-in on the high-impact scenarios from the cost-effectiveness expansion path figures can be found in Supplementary file 2 .

\section{HIV Results}

In South-East Asia, the intervention focused on FSWs at 95\% coverage would be the most cost-effective intervention and is thus adopted first on the expansion path (Table 14). FSW interventions are both behavioural and biomedical. FSWs face very high risk, often the highest of any population group, and given that incidence is part of the cost-efficiency equation, FSW interventions are expected to be highly costeffective (the more infections there are to avert, the higher the cost-effectiveness). However, it is important to note that FSWs may become hard to reach a high level of coverage given the nature of discrimination against them, and the lack
Table 13. Intervention Costing Assumptions for TB

\begin{tabular}{|c|c|c|}
\hline $\begin{array}{l}\text { Patient Costs (I\$ 2010) (Regional Average } \\
\text { Unit Costs Per Person Reached Per Year) }\end{array}$ & $\begin{array}{c}\text { Eastern Sub- } \\
\text { Saharan } \\
\text { Africa }\end{array}$ & $\begin{array}{l}\text { Southeast } \\
\text { Asia }\end{array}$ \\
\hline \multicolumn{3}{|l|}{ Detection } \\
\hline \multicolumn{3}{|l|}{ Smear microscopy } \\
\hline $\begin{array}{l}\text { Diagnostic test for passive TB case finding, } \\
\text { BAC+ cases }\end{array}$ & 1.20 & 1.20 \\
\hline $\begin{array}{l}\text { Diagnostic tests for adults in } \mathrm{HH} \text {-contact } \\
\text { tracing }\end{array}$ & 1.20 & 1.20 \\
\hline $\begin{array}{l}\text { Diagnostic tests for children in } \mathrm{HH} \text {-contact } \\
\text { tracing }\end{array}$ & 1.20 & 1.20 \\
\hline Diagnostic test for retreatment cases & 1.20 & 1.20 \\
\hline Diagnostic test for child cases, BAC+ cases & 1.20 & 1.20 \\
\hline Diagnostic test for HIV+ cases, BAC+ cases & 1.20 & 1.20 \\
\hline Test to monitor treatment for new cases & 1.20 & 1.20 \\
\hline $\begin{array}{l}\text { Test to monitor treatment for retreatment } \\
\text { cases }\end{array}$ & 1.80 & 1.80 \\
\hline Test to monitor treatment for MDR-TB cases & 7.21 & 7.21 \\
\hline \multicolumn{3}{|l|}{ Culture } \\
\hline $\begin{array}{l}\text { Diagnostic test for passive TB case finding, } \\
\text { BAC+ cases }\end{array}$ & 10.59 & 10.59 \\
\hline $\begin{array}{l}\text { Diagnostic tests for adults in } \mathrm{HH} \text {-contact } \\
\text { tracing }\end{array}$ & 10.59 & 10.59 \\
\hline $\begin{array}{l}\text { Diagnostic tests for children in } \mathrm{HH} \text {-contact } \\
\text { tracing }\end{array}$ & 10.59 & 10.59 \\
\hline $\begin{array}{l}\text { Diagnostic test for smear negative or Xpert } \\
\text { negative }\end{array}$ & 10.59 & 10.59 \\
\hline Diagnostic test for extra pulmonary TB & 10.59 & 10.59 \\
\hline Diagnostic test for child cases, BAC+ cases & 10.59 & 10.59 \\
\hline Diagnostic test for HIV+ cases, BAC+ cases & 10.59 & 10.59 \\
\hline Test to monitor treatment for new cases & 21.17 & 21.17 \\
\hline $\begin{array}{l}\text { Test to monitor treatment for retreatment } \\
\text { cases }\end{array}$ & 31.76 & 31.76 \\
\hline Resistance testing for new cases (FLD) & 10.59 & 10.59 \\
\hline Resistance testing for retreatment cases (FLD) & 10.59 & 10.59 \\
\hline $\begin{array}{l}\text { Resistance testing/monitoring for MDR-TB } \\
\text { cases (FLD) }\end{array}$ & 127.03 & 127.03 \\
\hline $\begin{array}{l}\text { Resistance testing/monitoring for MDR-TB } \\
\text { cases (SLD) }\end{array}$ & 127.03 & 127.03 \\
\hline Resistance testing for HIV+ cases & 10.59 & 10.59 \\
\hline Resistance testing for child cases & 10.59 & 10.59 \\
\hline Resistance testing for MDR-TB contact tracing & 10.59 & 10.59 \\
\hline \multicolumn{3}{|l|}{ Molecular: Xpert } \\
\hline $\begin{array}{l}\text { Diagnostic test for passive TB case finding, } \\
\text { BAC+ cases }\end{array}$ & 9.98 & 9.98 \\
\hline $\begin{array}{l}\text { Diagnostic tests for adults in } \mathrm{HH} \text {-contact } \\
\text { tracing }\end{array}$ & 9.98 & 9.98 \\
\hline $\begin{array}{l}\text { Diagnostic tests for children in } \mathrm{HH} \text {-contact } \\
\text { tracing }\end{array}$ & 9.98 & 9.98 \\
\hline Diagnostic test for smear negative TB & 9.98 & 9.98 \\
\hline Diagnostic test for extra pulmonary TB & 9.98 & 9.98 \\
\hline Diagnostic test for child cases, BAC+ cases & 9.98 & 9.98 \\
\hline Diagnostic test for HIV+ cases, BAC+ cases & 9.98 & 9.98 \\
\hline Test to monitor treatment for new cases & 19.96 & 19.96 \\
\hline $\begin{array}{l}\text { Test to monitor treatment for retreatment } \\
\text { cases }\end{array}$ & 29.94 & 29.94 \\
\hline Resistance testing for new cases & 9.98 & 9.98 \\
\hline
\end{tabular}


Table 13. Continued

\begin{tabular}{|c|c|c|}
\hline $\begin{array}{l}\text { Patient Costs (I\$ 2010) (Regional Average } \\
\text { Unit Costs Per Person Reached Per Year) }\end{array}$ & $\begin{array}{c}\text { Eastern Sub- } \\
\text { Saharan } \\
\text { Africa }\end{array}$ & $\begin{array}{l}\text { Southeast } \\
\text { Asia }\end{array}$ \\
\hline Resistance testing for retreatment cases & 9.98 & 9.98 \\
\hline Resistance testing for MDR-TB cases & 119.76 & 119.76 \\
\hline Resistance testing for HIV+ cases & 9.98 & 9.98 \\
\hline Resistance testing for child cases & 9.98 & 9.98 \\
\hline Resistance testing for MDR-TB contact tracing & 9.98 & 9.98 \\
\hline \multicolumn{3}{|l|}{ X-rays, Full Chest } \\
\hline $\begin{array}{l}\text { Screening for passive TB case finding, BAC+ } \\
\text { cases }\end{array}$ & 10.00 & 10.00 \\
\hline $\begin{array}{l}\text { Diagnostic tests for adults in } \mathrm{HH} \text {-contact } \\
\text { tracing }\end{array}$ & 10.00 & 10.00 \\
\hline $\begin{array}{l}\text { Diagnostic tests for children in } \mathrm{HH} \text {-contact } \\
\text { tracing }\end{array}$ & 10.00 & 10.00 \\
\hline Screening for smear negative TB & 10.00 & 10.00 \\
\hline Screening for extra pulmonary TB & 10.00 & 10.00 \\
\hline Screening for child cases, BAC+ cases & 10.00 & 10.00 \\
\hline Screening for HIV+ cases, BAC+ cases & 10.00 & 10.00 \\
\hline Test to monitor treatment for new cases & 20.00 & 20.00 \\
\hline $\begin{array}{l}\text { Test to monitor treatment for retreatment } \\
\text { cases }\end{array}$ & 30.00 & 30.00 \\
\hline Test to monitor treatment for MDR-TB cases & 30.00 & 30.00 \\
\hline \multicolumn{3}{|l|}{ Treatment } \\
\hline \multicolumn{3}{|l|}{ First line treatment } \\
\hline First-line TB drugs, initial treatment (adults) & 30.93 & 30.93 \\
\hline First-line TB drugs, initial treatment (children) & 24.12 & 24.12 \\
\hline First-line TB drugs, retreatment & 98.90 & 98.90 \\
\hline \multicolumn{3}{|l|}{ MDR and XDR TB } \\
\hline Second-line TB drugs & 1866.24 & 1866.24 \\
\hline XDR treatment & 7602.00 & 7602.00 \\
\hline MDR-adverse events and palliative care & 120.00 & 120.00 \\
\hline XDR-adverse events and palliative care & 120.00 & 120.00 \\
\hline \multicolumn{3}{|l|}{ Collaborative TB and HIV/AIDS interventions } \\
\hline HIV testing and counselling & 4.80 & 4.80 \\
\hline Prioritization of ART for TB-HIV co-infected & 110.00 & 110.00 \\
\hline $\begin{array}{l}\text { Isoniazid preventive therapy for adults and } \\
\text { children with HIV and on ART without TB }\end{array}$ & 5.43 & 5.43 \\
\hline $\begin{array}{l}\text { Isoniazid preventive therapy for adults and } \\
\text { children with HIV and not on ART without TB }\end{array}$ & 5.43 & 5.43 \\
\hline \multicolumn{3}{|c|}{ Preventive therapy for adults and children through $\mathrm{HH}$-contact tracing } \\
\hline Preventive therapy for children without TB & 5.43 & 5.43 \\
\hline Preventive therapy for adults without TB & 5.43 & 5.43 \\
\hline \multicolumn{3}{|l|}{ MDR case management } \\
\hline MDR case management & 11886.99 & 7135.00 \\
\hline \multicolumn{3}{|l|}{ Health systems costs } \\
\hline First line: Hospitalization and Ambulatory Care & 23.69 & 55.66 \\
\hline $\begin{array}{l}\text { Second line: Hospitalization and Ambulatory } \\
\text { Care }\end{array}$ & 1366.60 & 2854.58 \\
\hline
\end{tabular}

Abbreviations: TB, tuberculosis; $\mathrm{HH}$, household; BAC, blood alcohol content; FLD, first line drugs, SLD, second line drugs; MDR, multidrug-resistant; XDR, extensively drug-resistant; ART, antiretroviral therapy. of human-rights based platforms for functional intervention strategies. VMMC at $95 \%$ coverage would be the most costeffective in eastern sub-Saharan Africa (Table 15). VMMC is an essential component of HIV prevention and is widely recognized as cost-effective in several African countries, ${ }^{66,67}$ our study corroborated this conclusion. VMMC is biomedical and behavioural, and also incidence reducing, and in these respects is like the FSW intervention mentioned in the previous paragraph.

In both regions, the largest HLY gains come through a combination of interventions at 95\% coverage including HIV testing services, ART treatment as prevention for all HIV positive adults, children and PMTCT Option $\mathrm{B}+$, mass media communication designed to increase demand and improve the use of condoms, condom provision, interventions among FSWs, PWID community outreach and peer education, youthfocused interventions and management of STIs (CB395) (Tables 14 and 15). This shows that even in concentrated epidemic settings, HIV requires a combination approach, built around ART expansion, to achieve the objectives for overall burden reduction. This means that a full suite of comprehensive approaches needs to be deployed.

Comparing the "current" intervention, at the reference time of 2010, to the expansion path: In southeast Asia, the current intervention is seen to be more cost-effective than any of the combination interventions studied in this analysis (Figure 1) and is therefore on the expansion path. Details on the expansion paths for eastern sub-Saharan Africa can be found in Figure 2.

\section{Tuberculosis Results}

$\mathrm{TB}$ treatments are known to be highly cost-effective. ${ }^{7}$ In both regions, the basic care-and-control scenario including treatment (FLD [first line drugs] FLD + SLD [second line drugs]), detection (Smear + X-ray + Culture) and drug susceptibility cannot be unbundled since screening cannot be implemented separately from treatment. The expansion path shows increasing levels of coverage culminating at the highest (95\%) in order to achieve maximum health gains.

Following the programmatic expansion path, and as resources become available, more interventions with lower cost-effectiveness but which are still cost-effective would be added. In eastern sub-Saharan African, where the global TB/ HIV burden is high, preventive therapy for HIV-positive TB cases not on ART and on ART with LTBI, preventive therapy for children with LTBI and ART prioritization for notified HIV-positive TB cases would be progressively combined to the basic care-and-control scenario. In southeast Asia, ART prioritization for notified HIV-positive TB cases would be added to the basic care-and-control scenario.

For southeast Asia we observe that an average package of current interventions for the reference time of 2010 is on the expansion path (Figure 3), similar to the HIV results discussed above. In eastern sub-Saharan Africa, therefore, the question is not finetuning coverage levels, but rather programmatic expansion (Figure 4) since average current practice at the reference time of 2010 is on the programmatic expansion path. 
Table 14. Costs, Effects and Cost-Effectiveness of HIV Interventions in Southeast Asia Over 100 Years

\begin{tabular}{|c|c|c|c|c|c|c|c|}
\hline & Intervention & $\begin{array}{l}\text { Population } \\
\text { Coverage } \\
\text { (\%) }\end{array}$ & $\begin{array}{l}\text { Total Costs } \\
\text { Per } 10 \text { Million } \\
\text { Population } \\
\text { (Million I\$ 2010) }\end{array}$ & $\begin{array}{l}\text { HLYs (million } \\
\text { HLY) Gained } \\
\text { Per } 10 \text { Million } \\
\text { Population }\end{array}$ & $\begin{array}{l}\text { ACER (I\$ } \\
\text { Per HLY) }\end{array}$ & $\begin{array}{l}\text { ICER (I\$ Per HLY) } \\
\text { (Programmatic } \\
\text { expansion path) }\end{array}$ & $\begin{array}{c}\text { ICER (I\$ Per } \\
\text { HLY) (Health } \\
\text { Maximizing } \\
\text { Expansion Path) }\end{array}$ \\
\hline Current & Current scenario & & 1339.1 & 44.7 & 30 & & \\
\hline CB350 & $\begin{array}{l}\text { TasP + MMCO + FSW + PWID + MSM + } \\
\text { YFI + Management of STIS + VMMC }\end{array}$ & 50 & 4193.6 & 49.2 & 85 & Dominated & 201.1 \\
\hline CB395 & $\begin{array}{l}\text { TasP + MMCO + FSW + PWID + MSM + } \\
\mathrm{YFI} \mathrm{+} \mathrm{Management} \mathrm{of} \mathrm{STIs} \mathrm{+} \mathrm{VMMC}\end{array}$ & 95 & 6887.5 & 53.0 & 130 & 210.3 & 2781.0 \\
\hline FSW95 & Female sex workers & 95 & 124.3 & 20.8 & 6 & 6.0 & 6.0 \\
\hline MMCO95 & $\begin{array}{l}\text { Mass media communication designed } \\
\text { to increase demand and improve use of } \\
\text { condoms, and condom provision }\end{array}$ & 95 & 313.4 & 29.9 & 10 & Dominated & 20.7 \\
\hline
\end{tabular}

Abbreviations: HLY, healthy life year; TasP, Treatment as prevention; MMCO, mass media communication and condom provision; FSW, female sex worker; PWID, people who inject drug; MSM, Men who have sex with men; VMMC, voluntary medical male circumcision; YFI, youth focused intervention; PMTCT, prevention of mother-to-child transmission; STI, sexually transmitted infection; ACER, average cost-effectiveness ratio; ICER, incremental cost-effectiveness ratio.

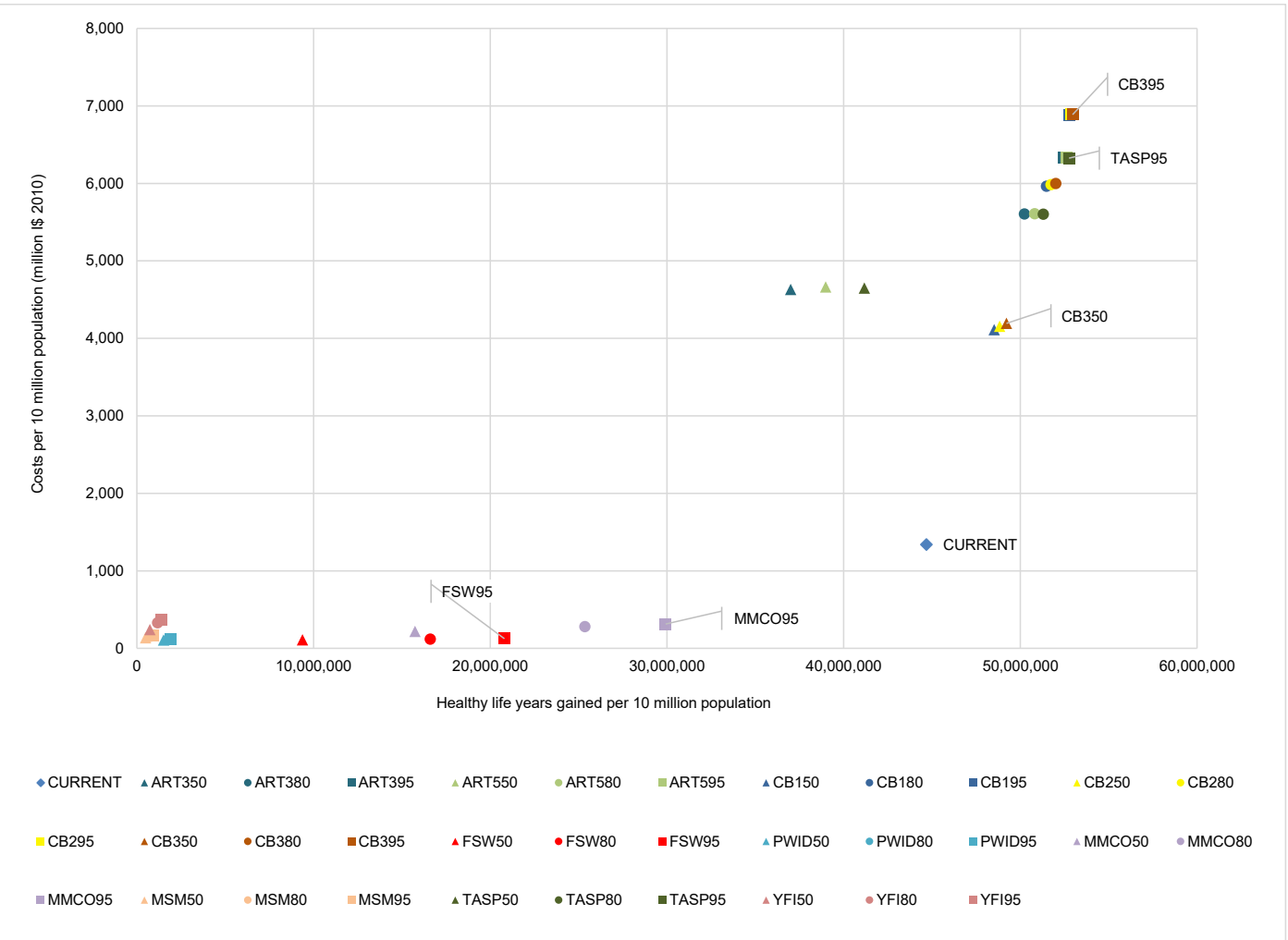

Figure 1. Cost-Effectiveness Expansion Path for HIV Interventions in Southeast Asia. *Refer to Table 1 for intervention label *50, 80 and 95 at the end of each label refer to coverages of $50 \%, 80 \%$ and $95 \%$ respectively.

\section{Malaria Results}

Plasmodium vivax Malaria Results

In South-East Asia, management of severe cases is the most cost-effective intervention (Table 18). As severe malaria is fatal in nearly all cases without treatment, successfully treating the severe cases at reasonable cost results in important health benefits in terms of averted mortality. However, promptly treating uncomplicated malaria is necessary to avoid severe cases, as well as are preventive interventions to reduce case incidence. Prevention and case management are therefore the keys to cost-effective control of malaria.

The package of average current interventions at the 
Table 15. Costs, Effects and Cost-Effectiveness of HIV Interventions in Eastern Sub-Saharan Africa Over 100 Years

\begin{tabular}{|c|c|c|c|c|c|c|c|}
\hline & Intervention & $\begin{array}{l}\text { Population } \\
\text { Coverage (\%) }\end{array}$ & $\begin{array}{c}\text { Total Costs } \\
\text { Per } 10 \text { Million } \\
\text { Population } \\
\text { (Million I\$ 2010) }\end{array}$ & $\begin{array}{l}\text { HLYs (Million } \\
\text { Hly) Gained } \\
\text { Per } 10 \text { Million } \\
\text { Population }\end{array}$ & $\begin{array}{l}\text { ACER (I\$ } \\
\text { Per HLY) }\end{array}$ & $\begin{array}{l}\text { ICER (I\$ Per HLY) } \\
\text { (Programmatic } \\
\text { Expansion Path) }\end{array}$ & $\begin{array}{c}\text { ICER (I\$ per } \\
\text { HLY) (Health } \\
\text { Maximizing } \\
\text { Expansion Path) }\end{array}$ \\
\hline Current & Current Scenario & & 10682 & 513 & 21 & & \\
\hline CB295 & $\begin{array}{l}\text { ART5 + MMCO + FSW + PWID + MSM } \\
+ \text { YFI + Management of Sexually } \\
\text { Transmitted Infections + VMMC }\end{array}$ & 95 & 8745 & 604 & 14 & 28.9 & Dominated \\
\hline CB380 & $\begin{array}{l}\text { TasP + MMCO + FSW + PWID + MSM } \\
+ \text { YFI + Management of STIS + VMMC }\end{array}$ & 80 & 8386 & 594 & 14 & Dominated & 28.7 \\
\hline CB395 & $\begin{array}{l}\text { TasP + MMCO + FSW + PWID + MSM } \\
+ \text { YFI + Management of STIS + VMMC }\end{array}$ & 95 & 8781 & 605 & 15 & Dominated & 34.2 \\
\hline VMMC95 & Voluntary medical male circumcision & 95 & 704 & 326 & 2 & 2.2 & 2.2 \\
\hline
\end{tabular}

Abbreviations: ART, antiretroviral therapy; HLY, healthy life year; TasP, Treatment as prevention; MMCO, mass media communication and condom provision; FSW, female sex worker; PWID, people who inject drug; MSM, Men who have sex with men; VMMC, voluntary medical male circumcision; YFI, youth focused intervention; STI, sexually transmitted infection; ACER, average cost-effectiveness ratio; ICER, incremental cost-effectiveness ratio.

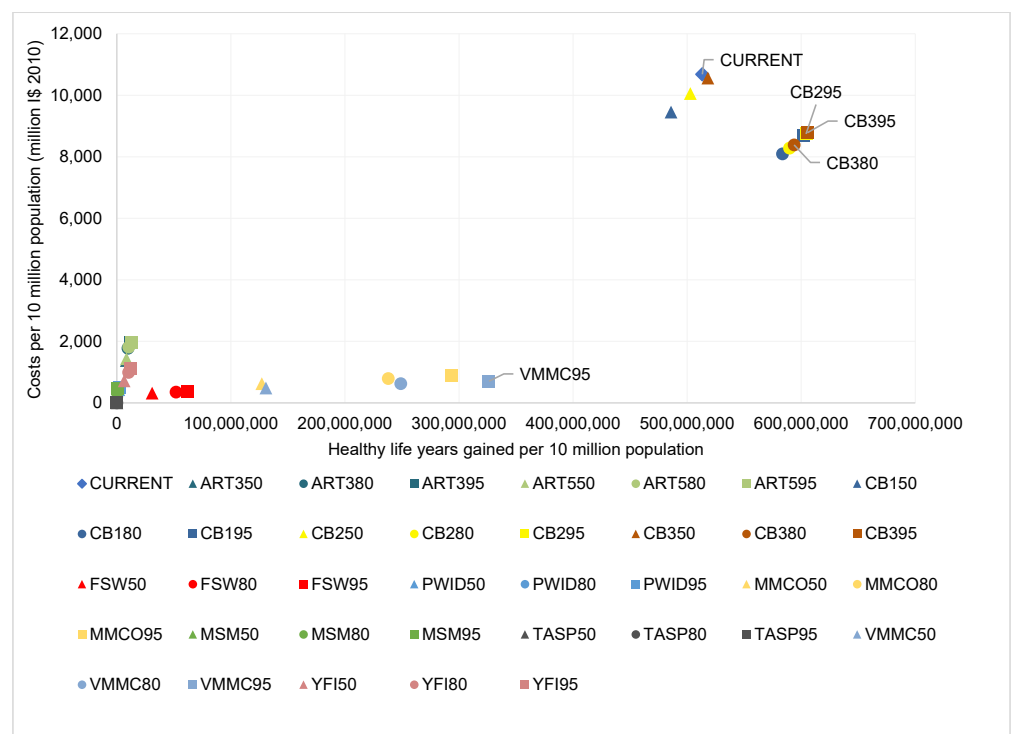

Figure 2. Cost-Effectiveness Expansion Path for HIV Interventions in Eastern Sub-Saharan Africa. *Refer to Table 1 for interventions label ${ }^{*} 50,80$ and 95 at the end of each label refer to coverage of $50 \%, 80 \%$ and $95 \%$ respectively. Abbreviations: ART, antiretroviral therapy; HLY, healthy life year; TasP, Treatment as prevention; MMCO, mass media communication and condom provision; FSW, female sex worker; PWID, people who inject drug; MSM, Men who have sex with men; VMMC, voluntary medical male circumcision; YFI, youth focused intervention.

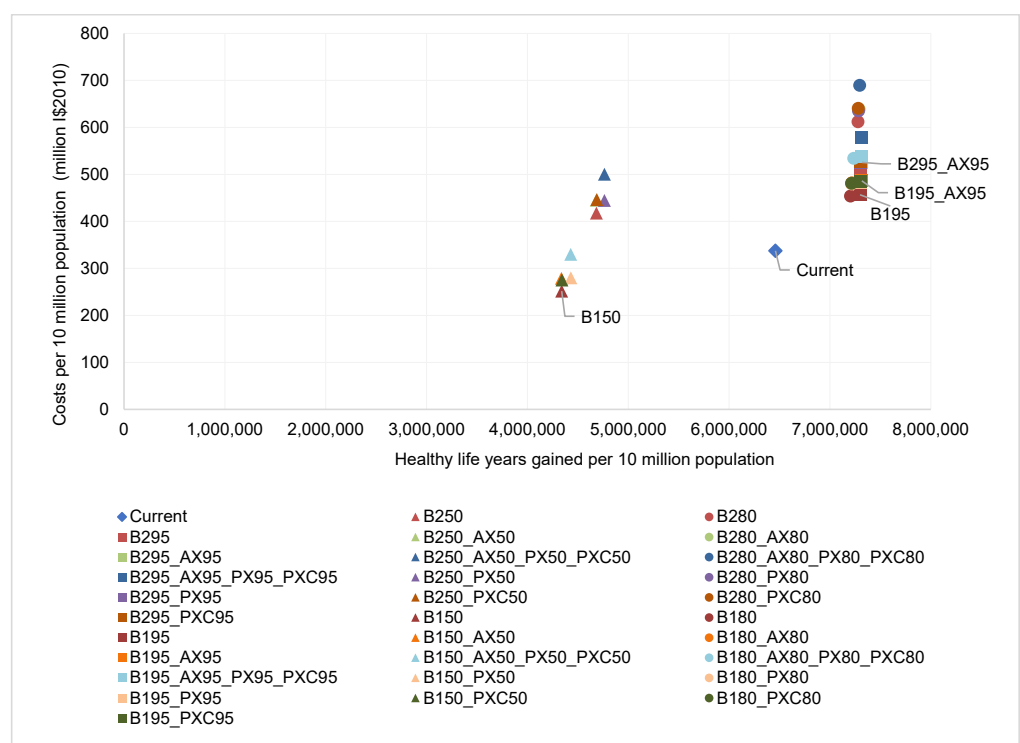

Figure 3. Cost-Effectiveness Expansion Path for TB Interventions in Southeast Asia. * Refer to Table 2 for interventions label *50, 80 and 95 at the end of each label refer to coverage of $50 \%, 80 \%$ and $95 \%$ respectively. 
Table 16. Costs, Effects and Cost-Effectiveness of TB Interventions in Southeast Asia Over 100 Years

\begin{tabular}{|c|c|c|c|c|c|c|c|}
\hline & Intervention & $\begin{array}{l}\text { Population } \\
\text { Coverage } \\
(\%)\end{array}$ & $\begin{array}{l}\text { Total Costs } \\
\text { Per } 10 \text { Million } \\
\text { Population } \\
\text { (Million I\$ } \\
\text { 2010) } \\
\end{array}$ & $\begin{array}{l}\text { HLYs (Million } \\
\text { HLY) Gained } \\
\text { Per } 10 \text { Million } \\
\text { Population }\end{array}$ & $\begin{array}{l}\text { ACER (I\$ } \\
\text { Per HLY) }\end{array}$ & $\begin{array}{l}\text { ICER (I\$ Per HLY) } \\
\text { (Programmatic } \\
\text { Expansion Path) }\end{array}$ & $\begin{array}{c}\text { ICER (I\$ Per } \\
\text { HLY) (Health } \\
\text { Maximizing } \\
\text { Expansion Path) }\end{array}$ \\
\hline Current & Current scenario & & 337.5 & 6.5 & 52 & & \\
\hline B295_AX95 & $\begin{array}{l}\text { Treatment }(F L D+S L D)+\text { Detection (Xpert + } \\
\text { X-ray + Culture) + Drug susceptibility testing } \\
+ \text { ART prioritization for TB cases }\end{array}$ & 95 & 525.6 & 7.3 & 72 & Dominated & 53279.4 \\
\hline B150 & $\begin{array}{l}\text { Treatment (FLD + SLD) + Detection (Smear } \\
+ \text { X-ray + Culture) + Drug susceptibility } \\
\text { testing }\end{array}$ & 50 & 251.7 & 4.3 & 58 & 58.0 & 58.0 \\
\hline B195 & $\begin{array}{l}\text { Treatment (FLD + SLD) + Detection (Smear } \\
+ \text { X-ray + Culture) + Drug susceptibility } \\
\text { testing }\end{array}$ & 95 & 456.7 & 7.3 & 63 & 69.3 & 69.3 \\
\hline B195_AX95 & $\begin{array}{l}\text { Treatment (FLD + SLD) + Detection (Smear } \\
+ \text { X-ray + Culture) + Drug susceptibility } \\
\text { testing + ART prioritization for TB cases }\end{array}$ & 95 & 486.3 & 7.3 & 66 & 1673.9 & 1673.9 \\
\hline
\end{tabular}

Abbreviations: HLY, healthy life year; FLD, first line drugs; SLD, second line drugs; TB, tuberculosis; ACER, average cost-effectiveness ratio; ICER, incremental cost-effectiveness ratio.

Table 17. Costs, Effects and Cost-Effectiveness of TB Interventions in Eastern Sub-Saharan Africa Over 100 Years

\begin{tabular}{|c|c|c|c|c|c|c|c|}
\hline & Intervention & $\begin{array}{l}\text { Population } \\
\text { Coverage } \\
(\%)\end{array}$ & $\begin{array}{l}\text { Total Costs } \\
\text { Per } 10 \text { Million } \\
\text { Population } \\
\text { (Million I\$ } \\
\text { 2010) }\end{array}$ & $\begin{array}{l}\text { HLYs (Million } \\
\text { HLY) Gained } \\
\text { Per } 10 \text { Million } \\
\text { Population }\end{array}$ & $\begin{array}{l}\text { ACER (I\$ } \\
\text { Per HLY) }\end{array}$ & $\begin{array}{l}\text { ICER (I\$ } \\
\text { Per HLY) } \\
\text { (Programmatic } \\
\text { Expansion } \\
\text { Path) }\end{array}$ & $\begin{array}{l}\text { ICER (I\$ Per } \\
\text { HLY) (Health } \\
\text { Maximizing } \\
\text { Expansion } \\
\text { Path) }\end{array}$ \\
\hline Current & Current Scenario & & 516 & 20 & 26 & & \\
\hline B295 & $\begin{array}{l}\text { Treatment (FLD + SLD) + Detection (Xpert + } \\
\text { X-ray + Culture) + Drug susceptibility testing }\end{array}$ & 95 & 413 & 20 & 21 & Dominated & 21.7 \\
\hline B295_AX95 & $\begin{array}{l}\text { Treatment }(F L D+S L D)+\text { Detection (Xpert + } \\
\text { X-ray + Culture) + Drug susceptibility testing } \\
+ \text { ART }^{\circ} \text { prioritization for TB cases }\end{array}$ & 95 & 431 & 20 & 21 & Dominated & 501.2 \\
\hline B150 & $\begin{array}{l}\text { Treatment (FLD + SLD) + Detection (Smear + } \\
\text { X-ray + Culture) + Drug susceptibility testing }\end{array}$ & 50 & 239 & 12 & 20 & 19.7 & 19.7 \\
\hline B195 & $\begin{array}{l}\text { Treatment (FLD + SLD) + Detection (Smear + } \\
\text { X-ray + Culture) + Drug susceptibility testing }\end{array}$ & 95 & 536 & 20 & 27 & 37.3 & Dominated \\
\hline $\begin{array}{l}\text { B195_AX95_ } \\
\text { PX95_PXC95 }\end{array}$ & $\begin{array}{l}\text { Treatment (FLD + SLD) + Detection (Smear } \\
+ \text { X-ray + Culture) + Drug susceptibility } \\
\text { testing + } \text { ART }^{\circ} \text { prioritization for TB cases + } \\
\text { Preventive therapy + Preventive therapy for } \\
\text { children }\end{array}$ & 95 & 614 & 20 & 30 & $1,306.4$ & $15,413.7$ \\
\hline B195_PXC95 & $\begin{array}{l}\text { Treatment }(F L D+S L D)+\text { Detection (Smear + } \\
\text { X-ray + Culture) + Drug susceptibility testing } \\
+ \text { Preventive therapy for children }\end{array}$ & 95 & 545 & 20 & 27 & 316.2 & Dominated \\
\hline
\end{tabular}

Abbreviations: HLY, healthy life year; FLD, first line drugs; SLD, second line drugs; TB, tuberculosis; ACER, average cost-effectiveness ratio; ICER, incremental cost-effectiveness ratio.

reference time of 2010 is on the programmatic expansion path (Figure 5).

\section{Plasmodium falciparum Malaria Results}

As for the P. vivax malaria results, above, in eastern sub-Saharan Africa, management of severe cases is highly cost-effective. Following the programmatic expansion path, management of suspected uncomplicated cases and ITN would be added to form the treatment and incidence reducing combination, which is key to cost-effective control of malaria. Malaria vaccine with RTS,S, at 95\% coverage would complement the combination, adding to incidence reduction and maximizing the HLYs gained (Table 19).

The package of average coverage levels at the reference time of 2010 is well in the interior of the expansion path (Figure 6), highlighting the opportunity for efficiency gains without sacrificing programmatic criteria.

\section{Discussion}

\section{Principal Findings}

This study provides a quantitative assessment of allocative efficiency within three critical infectious-disease programme 


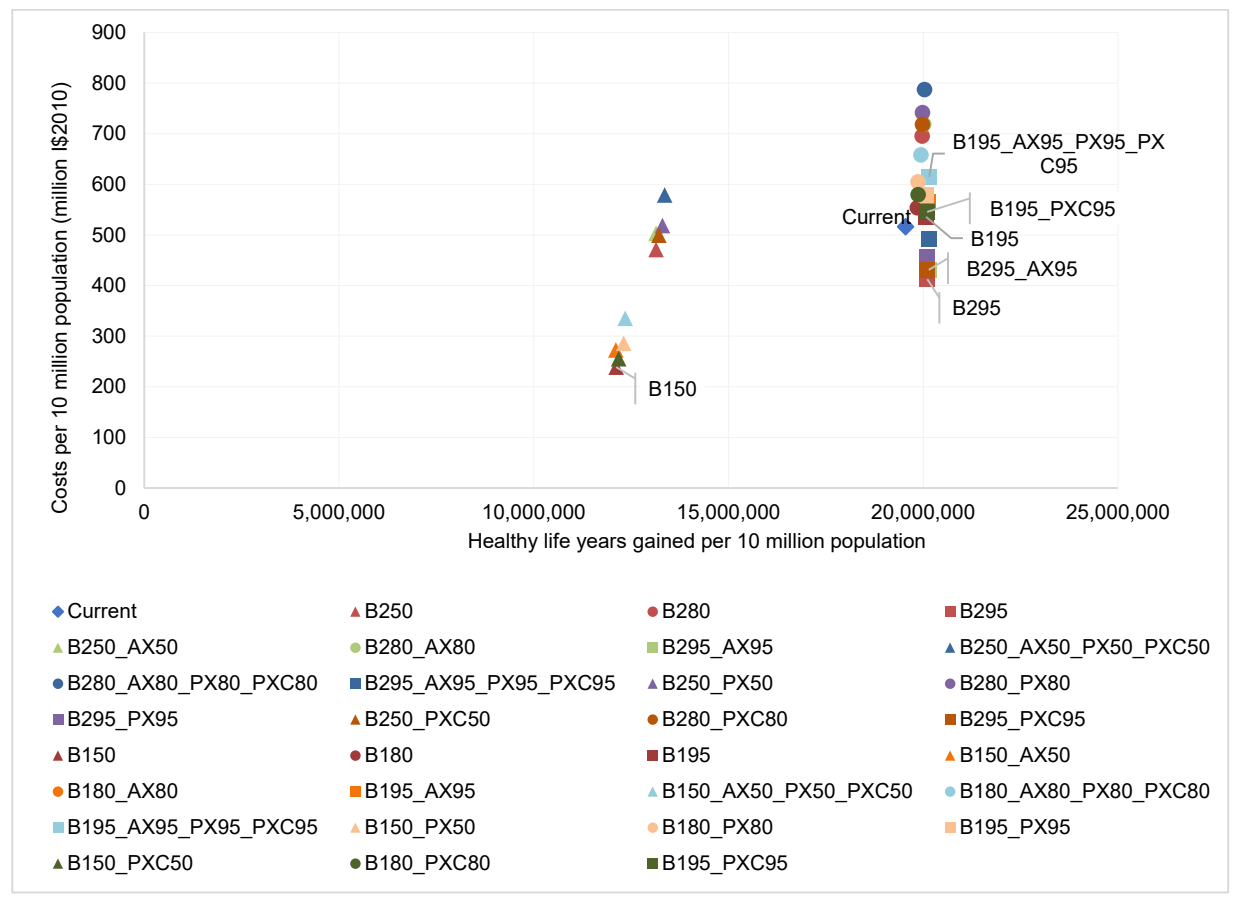

Figure 4. Cost-Effectiveness Expansion Path for TB Interventions in Eastern Sub-Saharan Africa. *Refer to Table 2 for interventions label *50, 80 and 95 at the end of each label refer to coverage of $50 \%, 80 \%$ and $95 \%$ respectively.

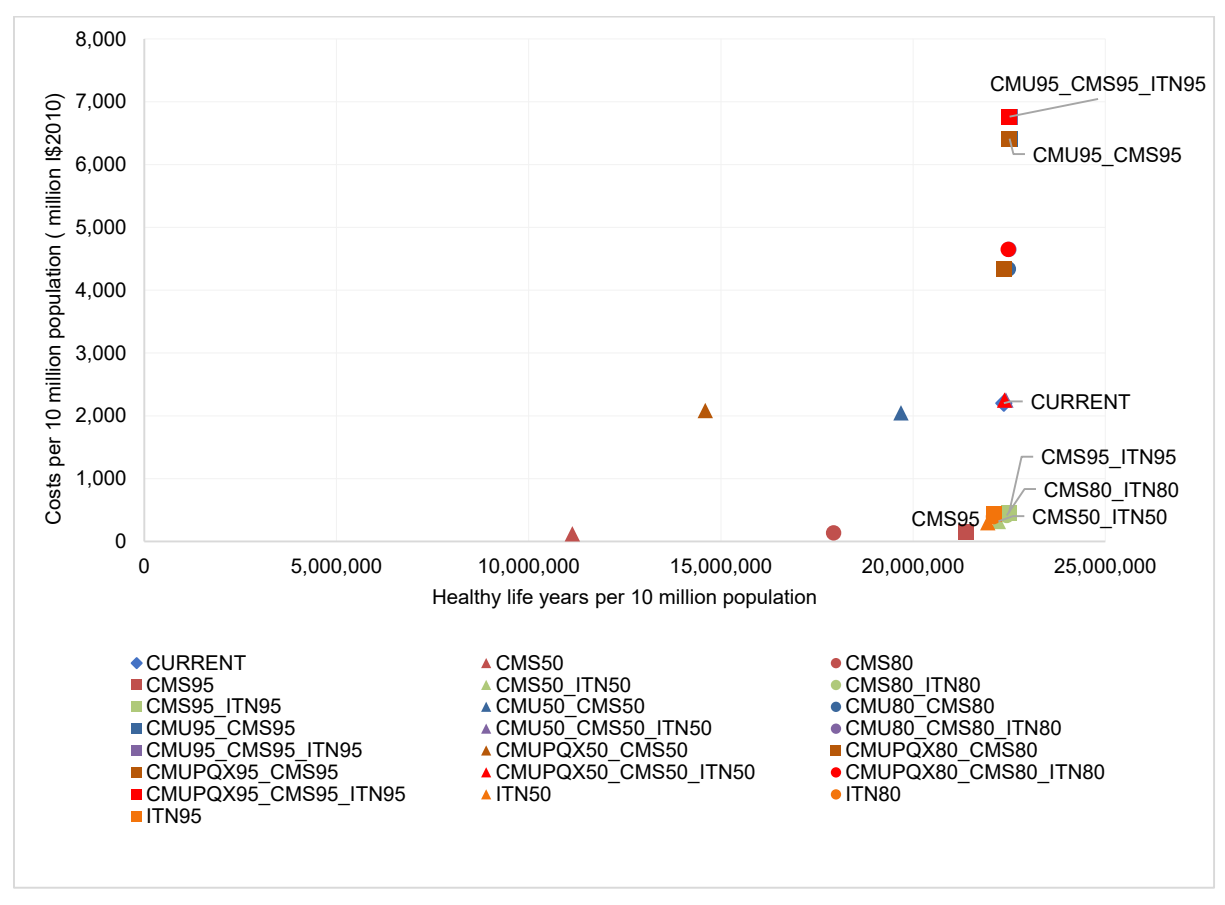

Figure 5. Cost-Effectiveness Expansion Path for Plasmodium vivax Malaria Interventions in Southeast Asia. *Refer to Table 5 for interventions label * 50,80 and 95 at the end of each label refer to coverage of $50 \%, 80 \%$ and $95 \%$ respectively. Abbreviation: ITN, insecticide-treated net.

areas: HIV, TB and Malaria. By retrospectively shining a spotlight on what programme development and scaling up achieved during the first decade of the 21st century (20002010), it aims to assist policy-makers in understanding what worked in obtaining value for money for HIV, TB and malaria.

Over the study period, the global community has done relatively well for HIV, TB, and malaria with respect to both efficiency and programmatic criteria. The role of international assistance, financial and technical, arguably was critical to these successes. Commonly used interventions, at the reference time of 2010, for HIV, TB and malaria were cost-effective, with cost-effectiveness ratios less than I\$ 100/ 
Table 18. Costs, Effects and Cost-Effectiveness of Plasmodium vivax Malaria Interventions in Southeast Asia Over 100 Years

\begin{tabular}{|c|c|c|c|c|c|c|c|c|c|}
\hline & Intervention & $\begin{array}{l}\text { Population } \\
\text { Coverage } \\
\text { (\%) }\end{array}$ & $\begin{array}{l}\text { Total Costs } \\
\text { Per } 10 \\
\text { Million } \\
\text { Population } \\
\text { (Million I\$ } \\
\text { 2010) }\end{array}$ & $\begin{array}{c}\text { HLYs } \\
\text { (Million } \\
\text { HLY) } \\
\text { Gained Per } \\
10 \text { Million } \\
\text { Population }\end{array}$ & $\begin{array}{l}\text { ACER (I\$ } \\
\text { per HLY) }\end{array}$ & $\begin{array}{c}\text { ICER (I\$ } \\
\text { Per HLY) } \\
\text { (Programmatic } \\
\text { Expansion } \\
\text { Path) }\end{array}$ & $\begin{array}{l}\text { ICER (I\$ Per } \\
\text { HLY) (Health } \\
\text { Maximizing } \\
\text { Expansion } \\
\text { Path) }\end{array}$ & $\begin{array}{l}\text { Cases (in } \\
\text { Million) Per } \\
10 \text { Million } \\
\text { Population }\end{array}$ & $\begin{array}{l}\text { Deaths (in } \\
\text { Million) Per } \\
10 \text { Million } \\
\text { Population }\end{array}$ \\
\hline Current & Current Scenario & & 2201.9 & 22.4 & 98.5 & - & - & -5.87 & -0.64 \\
\hline CMS95 & $\begin{array}{l}\text { Man agement of } \\
\text { severe cases }\end{array}$ & 95 & 146.0 & 21.4 & 6.8 & 6.8 & 6.8 & 0.12 & -0.31 \\
\hline CMS50_ITN50 & $\begin{array}{l}\text { Management of severe } \\
\text { cases }+ \text { Insecticide- } \\
\text { treated bed nets }\end{array}$ & 50 & 319.3 & 22.2 & 14.4 & Dominated & 203.9 & -5.70 & -0.32 \\
\hline CMS80_ITN80 & $\begin{array}{l}\text { Management of severe } \\
\text { cases }+ \text { Insecticide- } \\
\text { treated bed nets }\end{array}$ & 80 & 413.9 & 22.4 & 18.4 & Dominated & 437.4 & -5.76 & -0.33 \\
\hline CMS95_ITN95 & $\begin{array}{l}\text { Management of severe } \\
\text { cases }+ \text { Insecticide- } \\
\text { treated bed nets }\end{array}$ & 95 & 453.9 & 22.5 & 20.2 & 273.5 & 671.4 & -5.76 & -0.33 \\
\hline CMU95_CMS95 & $\begin{array}{l}\text { Management } \\
\text { of suspected } \\
\text { uncomplicated cases }+ \\
\text { Management of severe } \\
\text { cases }\end{array}$ & 95 & 6412.1 & 22.5 & 284.9 & Dominated & 415189.9 & -5.90 & -0.33 \\
\hline $\begin{array}{l}\text { CMU95_ } \\
\text { CMS95_ITN95 }\end{array}$ & $\begin{array}{l}\text { Management } \\
\text { of suspected } \\
\text { uncomplicated cases + } \\
\text { Management of severe } \\
\text { cases + Insecticide- } \\
\text { treated bed nets }\end{array}$ & 95 & 6762.9 & 22.5 & 300.5 & 445521.1 & Dominated & -5.90 & -0.33 \\
\hline
\end{tabular}

Abbreviation: HLY, healthy life year; ACER, average cost-effectiveness ratio; ICER, incremental cost-effectiveness ratio.

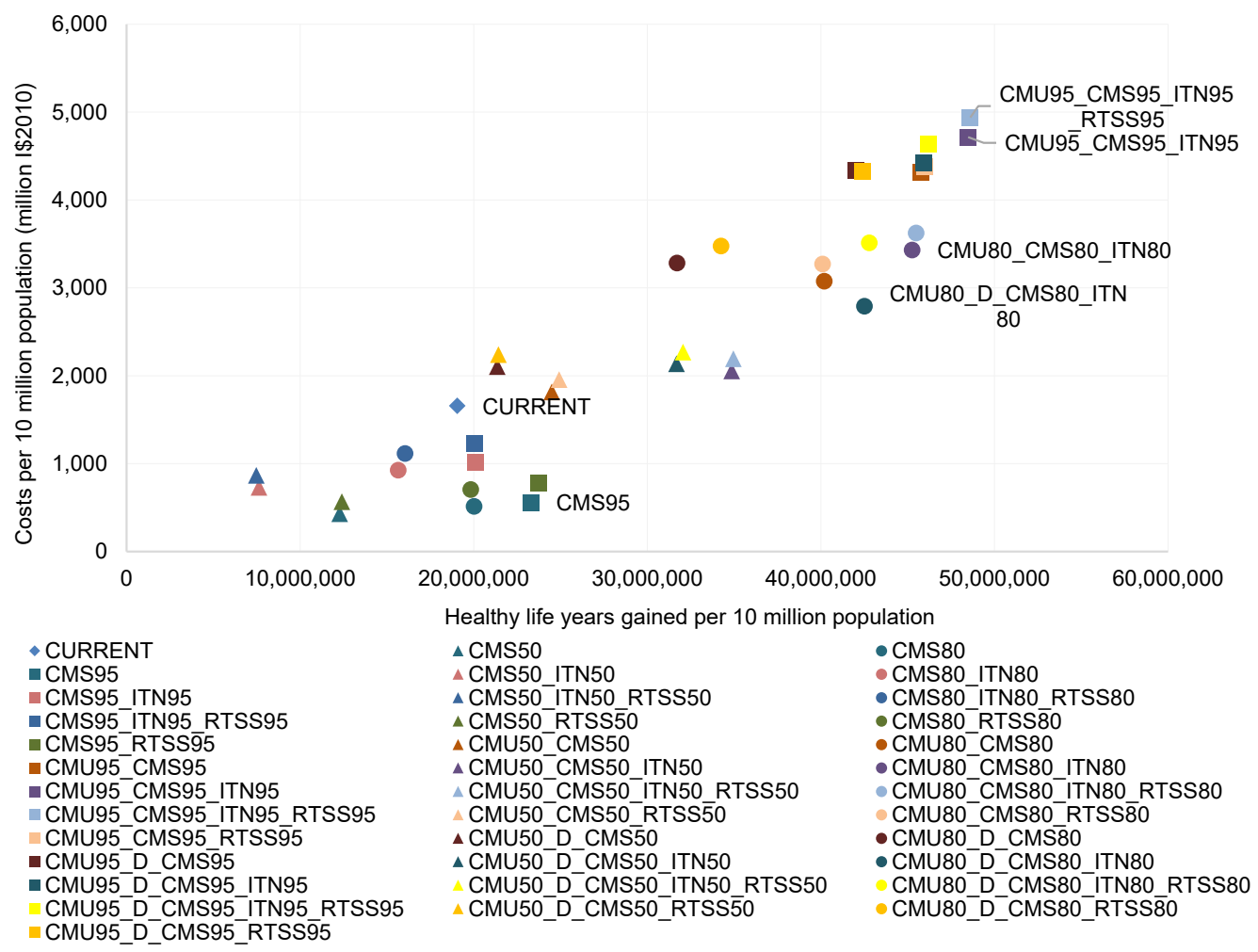

Figure 6. Cost-Effectiveness Expansion Path for P. falciparum Malaria Interventions in Eastern Sub-Saharan Africa. *Refer to Table 6 for interventions label ${ }^{*} 50,80$ and 95 at the end of each label refer to coverage of $50 \%, 80 \%$ and $95 \%$ respectively. 
Table 19. Costs, Effects and Cost-Effectiveness of Plasmodium falciparum Malaria Interventions in Eastern sub-Saharan Africa Over 100 Years

\begin{tabular}{|c|c|c|c|c|c|c|c|c|c|}
\hline & Intervention & $\begin{array}{l}\text { Population } \\
\text { Coverage } \\
(\%)\end{array}$ & $\begin{array}{l}\text { Total Costs } \\
\text { Per } 10 \\
\text { Million } \\
\text { Population } \\
\text { (Million I\$ } \\
\text { 2010) }\end{array}$ & $\begin{array}{l}\text { HLYs (million } \\
\text { HLY) Gained } \\
\text { Per } 10 \text { Million } \\
\text { Population }\end{array}$ & $\begin{array}{l}\text { ACER (I\$ } \\
\text { Per HLY) }\end{array}$ & $\begin{array}{c}\text { ICER (I\$ } \\
\text { per HLY) } \\
\text { (Programmatic } \\
\text { Expansion } \\
\text { Path) }\end{array}$ & $\begin{array}{l}\text { ICER (I\$ Per } \\
\text { HLY) (Health } \\
\text { Maximizing } \\
\text { Expansion } \\
\text { Path) }\end{array}$ & $\begin{array}{l}\text { Cases Averted } \\
\text { (in Million) } \\
\text { Per } 10 \text { Million } \\
\text { Population }\end{array}$ & $\begin{array}{c}\text { Deaths } \\
\text { Averted (in } \\
\text { Million)Per } \\
10 \text { Million } \\
\text { Population }\end{array}$ \\
\hline Current & Current scenario & & 1657.9 & 19.1 & 87.0 & & & -5.0 & -0.3 \\
\hline CMS95 & $\begin{array}{l}\text { Management of severe } \\
\text { cases }\end{array}$ & 95 & 556.8 & 23.3 & 23.9 & 23.9 & 23.9 & 0.5 & -0.4 \\
\hline $\begin{array}{l}\text { CMU80_ } \\
\text { CMS80_- } \\
\text { ITN80 }\end{array}$ & $\begin{array}{l}\text { Management } \\
\text { of suspected } \\
\text { uncomplicated cases }+ \\
\text { Management of severe } \\
\text { cases }+ \text { Insecticide- } \\
\text { treated bed nets }\end{array}$ & 80 & 3430.7 & 45.3 & 75.8 & Dominated & 232.2 & -15.8 & -0.7 \\
\hline $\begin{array}{l}\text { CMU95_ } \\
\text { CMS95_ } \\
\text { ITN95 }\end{array}$ & $\begin{array}{l}\text { Management } \\
\text { of suspected } \\
\text { uncomplicated cases + } \\
\text { Management of severe } \\
\text { cases + Insecticide- } \\
\text { treated bed nets }\end{array}$ & 95 & 4715.8 & 48.5 & 97.3 & 165.2 & 398.9 & -16.5 & -0.8 \\
\hline $\begin{array}{l}\text { CMU95_- } \\
\text { CMS95_- } \\
\text { ITN95_- } \\
\text { RTSS95 }\end{array}$ & $\begin{array}{l}\text { Management } \\
\text { of suspected } \\
\text { uncomplicated cases + } \\
\text { Management of severe } \\
\text { cases + Insecticide } \\
\text { treated bed nets + } \\
\text { Malaria vaccine with } \\
\text { RTS,S }\end{array}$ & 95 & 4939.3 & 48.6 & 101.6 & 1792.7 & 1792.7 & -16.5 & -0.8 \\
\hline $\begin{array}{l}\text { CMU80_D_ } \\
\text { CMS80_- } \\
\text { ITN80 }\end{array}$ & $\begin{array}{l}\text { Management } \\
\text { of suspected } \\
\text { uncomplicated cases } \\
\text { with treatment seeking } \\
\text { fever cases RDT tested + } \\
\text { Management of severe } \\
\text { cases + Insecticide- } \\
\text { treated bed nets }\end{array}$ & 80 & 2791.8 & 42.5 & 65.7 & Dominated & 116.4 & -15.6 & -0.7 \\
\hline
\end{tabular}

Abbreviations: HLY, healthy life year; RDT, Malaria rapid diagnostic test; ACER, average cost-effectiveness ratio; ICER, incremental cost-effectiveness ratio.

HLY saved for virtually not only optimal interventions but for most of those included in this study. This level of costeffectiveness would qualify interventions in the health subsector of HIV, TB, and malaria as "best buys" by conventional international standards such as those contained in the Appendix 3 of the Global Action Plan or the Prevention and Control of Non-Communicable Diseases, 2013-2020. ${ }^{68,69}$ It is essential to make this point when there is still a common perception that, for example, HIV and TB treatment regimens are prohibitively expensive compared to the health gains they offer. For southeast Asia, an average package of implemented interventions was found to be on the programmatic expansion path. In eastern sub-Saharan Africa, an average package of implemented interventions performed only slightly worse in cost-effectiveness terms than other combinations.

Comparison of the health-maximizing expansion path versus the programmatic expansion path shows different patterns depending on the disease and the region. However, where they differ, selection of the programmatic expansion path involves some opportunity costs in health terms. These less cost-effective but programmatically superior options therefore represent choices for policy-makers: in lowerresource settings there may be arguments in favour of the health-maximizing expansion path (since the alternative represents a long-term future optimum), whereas in less constrained settings it may make sense to observe the phasing of the programmatic expansion path. Actual choices in either type of setting may of course reflect the existence of assetspecific investments that have already been made.

\section{Policy Implications}

As we look across the health sector, especially in low-income countries and low- and middle-income countries, coverage levels typically are far below what is required for optimal disease control and elimination. Although more needs to be done, high coverage levels have already been achieved in many countries. This means that populations in need of health services have, at least on average, the opportunity to receive many of the services they require. In addition, however, when we look at the mix of interventions being implemented, we can see that actual practice is highly cost-effective, at least on average and at aggregate level. So, not only are coverage levels 
higher in HIV, TB and malaria than for other conditions in low-income countries and low- and middle-income countries but also the mix of interventions that are implemented and are highly cost-effective.

It may be hard to recognize how unusual this finding is. In almost no other area of global health is a similar case observed, at least outside of high-income countries. So, an interesting question to ask is why this has happened? Although we cannot know the answer for sure, we discuss some hypotheses that seem likely, based on our experience of performing economic evaluations across disease areas and countries during the past two decades.

First, it seems to us that these results are not independent of the fact substantial political will was generated not only in countries but also internationally for a massive push to increase coverage with effective intervention in these three disease areas. Significant international but more importantly domestic funding was moreover mobilized. Finally, HIV, $\mathrm{TB}$ and malaria programmes at global level have explicitly involved the systematic use of epidemiological and economic modelling evidence in the development of their policies for nearly 20 years, initially through the Joint United Nations Programme on HIV/AIDS (UNAIDS) Reference Group on Estimates Modelling and Projections but subsequently as a practice generalized across these three programme areas. The concept of evidence-based medicine, and evidencebased policy, is strongly anchored in the culture of these three disease programme areas.

As noted above, unprecedented levels of international donor funding and technical assistance has also arguably played a catalytic role, though the role of country financing has been larger in absolute terms. For example, the Global Fund has been able to provide a platform for international collective action independent from bilateral funding mechanisms and priorities and has also mobilized additional conditional funding for the three diseases, including from domestic sources, in the worst affected countries. This suggests the extent to which sustained collective action combined with evidence-based policies can have an impact on health outcomes even in the most resource-constrained settings.

Major donors such as Pepfar and the Global Fund and hybrid actors such as Unitaid have likely played an important catalysing role in not only financing interventions but also in market-shaping and in ensuring the presence of high quality technical advice and the application of international normative guidance, such as from WHO technical programmes, in the worst affected countries. While we cannot demonstrate this hypothesis scientifically, it is important to recall that the funding provided by Global Fund is, in many respects, only notional, as the absolute amounts provided cannot explain the overall increase in coverage witnessed since the beginning of the MDG era. Other funders have notably been important, including bilateral funders and Pepfar. But moreover, and quite importantly, all these actors have catalysed domestic financing that has become more important as economic growth has continued in these regions.

These observations are not a cause for complacency. Coverage levels are still inadequate from the standpoint of the economic and disease burden inflicted on the regions studied. Without continued and renewed efforts, regression to lower levels of epidemic control is inevitable and in some cases is now already being witnessed. International collective action must continue to support the case for this global public good.

\section{Limitations of the Analysis}

Our analysis is based on the average combination of interventions used in typical countries in the studied regions in the reference year 2010. Our results are intended to be indicative of performance relative to the global knowledge of best practice at the time, rather than prescriptive packages intended for countries to implement now. In addition, some key population groups were missing in our analysis particularly for the HIV analysis where, for example, the target group for sex workers could have included men rather than just women. Transgender people or prisoners could also have been represented. These choices, while bringing greater realism, would have been challenging to model. Some other limitations to this paper are related to the methodological approach to cost-effectiveness analysis in general and the GCEA in particular and are discussed in more details elsewhere. ${ }^{11,70}$

\section{Acknowledgements}

We would like to thank our colleagues from WHOCommunicable Diseases for their review and comments on this paper.

\section{Ethical issues \\ No ethical approval was sought as this is secondary data analysis.}

\section{Competing interests}

Authors declare that they have no competing interests.

\section{Authors' contributions}

AHR and JAL conceptualized, designed and drafted the manuscript. AHR, JAL, $\mathrm{CP}$ and OJTB acquired the data. AHR collated the database used and performed the cost-effectiveness analysis. AHR, JAL, CP, OJTB and EP contributed to the interpretation of the data, the edit and critical revision of the manuscript.

\section{Disclaimer}

AHR and EP are staff members of the WHO. The views expressed in this paper are solely the responsibility of the named authors and do not necessarily reflect the decisions or stated policy of the WHO or its Member states.

\section{Authors' affiliations}

${ }^{1}$ World Health Organization (WHO), Geneva, Switzerland. ${ }^{2}$ CERDI-CNRSIRD-UCA, Clermont-Ferrand, France. 'University of Strathclyde, Glasgow, UK. ${ }^{4}$ Avenir Health, Glastonbury, CT, USA. ${ }^{5}$ Swiss Tropical and Public Health Institute, Basel, Switzerland. 6University of Basel, Basel, Switzerland.

\section{Supplementary files}

Supplementary file 1. Costs, Effects and Incremental Cost-Effectiveness Per Disease, Per Region.

Supplementary file 2. Zoom in on the High-Impact Scenarios From the CostEffectiveness Expansion Path Figures.

\section{References}

1. United Nations. Sustainable development knowledge platform: 3. Ensure healthy lives and promote well-being for all at all ages. https://sdgs.un.org/ goals/goal3. Accessed August 14, 2017. Published 2016.

2. World Health Organization (WHO). Health, the SDGs and the Role of Universal Health Coverage: Next Steps in the South-East Asia Region, To Reach Those Being Left Behind. Regional Office for South-East Asia; 


\section{6.}

3. World Health Organization (WHO). Making Fair Choices on the Path to Universal Health Coverage: Final Report of the WHO Consultative Group on Equity and Universal Health Coverage. Geneva: WHO; 2014.

4. Verguet S, Kim JJ, Jamison DT. Extended cost-effectiveness analysis for health policy assessment: a tutorial. Pharmacoeconomics. 2016; 34(9):913-923. doi:10.1007/s40273-016-0414-z

5. Hogan DR, Baltussen R, Hayashi C, Lauer JA, Salomon JA. Cost effectiveness analysis of strategies to combat HIVIAIDS in developing countries. BMJ. 2005;331(7530):1431-1437. doi:10.1136/ bmj.38643.368692.68

6. Morel CM, Lauer JA, Evans DB. Cost effectiveness analysis of strategies to combat malaria in developing countries. BMJ. 2005; 331(7528):1299. doi:10.1136/bmj.38639.702384.AE

7. Baltussen R, Floyd K, Dye C. Cost effectiveness analysis of strategies for tuberculosis control in developing countries. BMJ. 2005; 331(7529):1364. doi:10.1136/bmj.38645.660093.68

8. Institute for Health Metrics and Evaluation. Global Health Data Exchange_ Countries. http://ghdx.healthdata.org/countries. Accessed January 16, 2017.

9. World Health Organization (WHO). World Malaria Report 2018. WHO; 2018.

10. Evans DB, Lim SS, Adam T, Edejer TT. Evaluation of current strategies and future priorities for improving health in developing countries. BMJ. 2005;331(7530):1457-1461. doi:10.1136/bmj.38658.675243.94

11. Evans DB, Edejer TT, Adam T, Lim SS. Methods to assess the costs and health effects of interventions for improving health in developing countries. BMJ. 2005;331(7525):1137-1140. doi:10.1136/bmj.331.7525.1137

12. Institute for Health Metrics and Evaluation. Global Burden of Disease 2010 Study Published. London: The Lancet; 2012.

13. Hutubessy R, Chisholm D, Edejer TT. Generalized cost-effectiveness analysis for national-level priority-setting in the health sector. Cost Eff Resour Alloc. 2003;1(1):8. doi:10.1186/1478-7547-1-8

14. Smith T, Killeen GF, Maire N, et al. Mathematical modeling of the impact of malaria vaccines on the clinical epidemiology and natural history of Plasmodium falciparum malaria: overview. Am J Trop Med Hyg. 2006;75(2 Suppl):1-10. doi:10.4269/ajtmh.2006.75.2_suppl.0750001

15. Lauer JA, Röhrich K, Wirth H, Charette C, Gribble S, Murray CJ. PopMod: a longitudinal population model with two interacting disease states. Cost Eff Resour Alloc. 2003;1(1):6. doi:10.1186/1478-7547-1-6

16. Briët OJ, Penny MA, Hardy D, et al. Effects of pyrethroid resistance on the cost effectiveness of a mass distribution of long-lasting insecticidal nets: a modelling study. Malar J. 2013;12:77. doi:10.1186/1475-2875-12-77

17. Corbel V, Chabi J, Dabiré RK, et al. Field efficacy of a new mosaic longlasting mosquito net (PermaNet 3.0) against pyrethroid-resistant malaria vectors: a multi centre study in Western and Central Africa. Malar J. 2010;9:113. doi:10.1186/1475-2875-9-113

18. Van Bortel W, Chinh VD, Berkvens D, Speybroeck N, Trung HD, Coosemans M. Impact of insecticide-treated nets on wild pyrethroid resistant Anopheles epiroticus population from southern Vietnam tested in experimental huts. Malar J. 2009;8:248. doi:10.1186/1475-2875-8-248

19. Howes RE, Dewi M, Piel FB, et al. Spatial distribution of G6PD deficiency variants across malaria-endemic regions. Malar J. 2013; 12:418. doi:10.1186/1475-2875-12-418

20. Ross A, Maire N, Molineaux L, Smith T. An epidemiologic model of severe morbidity and mortality caused by Plasmodium falciparum. Am J Trop Med Hyg. 2006;75(2 Suppl):63-73. doi:10.4269/ajtmh.2006.75.63

21. Goodman C, Coleman P, Mills A. Economic Analysis of Malaria Control in Sub-Saharan Africa. Geneva: Global Forum for Health Research; 2000.

22. World Health Organization (WHO). World Malaria Report 2012. WHO; 2012.

23. Briët OJ, Hardy D, Smith TA. Importance of factors determining the effective lifetime of a mass, long-lasting, insecticidal net distribution: a sensitivity analysis. Malar J. 2012;11:20. doi:10.1186/1475-2875-11-20

24. Penny M, Galactionova E, Tediosi F, et al. Public Health Impact and CostEffectiveness of the RTS,S Malaria Vaccine: Modelling and Simulation Results. Basel: Swiss TPH; 2013.

25. Brïet O, Galactionova K, Ross A, et al. Report on the generation of matrices with per-capita, age- and time-specific event rates for 'null', 'current' and 'intervention' scenarios, by country endemic for $P$. vivax for WHO sub-regions SEAR-D, EMR-D and SEAR-B, according to revised methodology. Internal report: unpublished. December 2015

26. Briët $\mathrm{O}$, Galactionova K. Report on the generation of matrices with per-capita, age- and time-specific event rates for 'null,' 'current' and 'intervention' scenarios, by country endemic for P. falciparum for WHO sub-regions Afr-D and Afr-E, and other malaria endemic countries situated in Africa, according to revised methodology. Internal report: unpublished. December 2015.

27. Spectrum [computer program]. https://avenirhealth.org/softwarespectrum.php.

28. Stover J. Projecting the demographic consequences of adult HIV prevalence trends: the Spectrum Projection Package. Sex Transm Infect. 2004;80 Suppl 1:i14-18. doi:10.1136/sti.2004.010157

29. Stover J, Bollinger L, Avila C. Estimating the impact and cost of the WHO 2010 recommendations for antiretroviral therapy. AIDS Res Treat. 2011;2011:738271. doi:10.1155/2011/738271

30. Stover J, Fidzani B, Molomo BC, Moeti T, Musuka G. Estimated HIV trends and program effects in Botswana. PLoS One. 2008;3(11):e3729. doi:10.1371/journal.pone.0003729

31. Stover J, Hallett TB, Wu Z, et al. How can we get close to zero? the potential contribution of biomedical prevention and the investment framework towards an effective response to HIV. PLOS One. 2014; 9(11):e111956. doi:10.1371/journal.pone.0111956

32. Stover J, Korenromp EL, Blakley M, et al. Long-term costs and health impact of continued global fund support for antiretroviral therapy. PLoS One. 2011;6(6):e21048. doi:10.1371/journal.pone.0021048

33. Stover J, Bollinger L. Financial resources required to achieve universal access to HIV prevention, treatment, care and support. Description of Interventions/Services Included in the Estimates of Resources Needed for HIV and AIDS. Methodological Annex-IV. Glastonbury, CT: Avenir Health; 2007.

34. Bollinger LA. How can we calculate the "E" in "CEA"? AIDS. 2008;22 Suppl 1:S51-57. doi:10.1097/01.aids.0000327623.31856.45

35. Avenir Health. Goals Manual: A Model for Estimating the Effects of Interventions and Resource Allocation on HIV Infections and Deaths. Glastonbury, CT: Avenir Health; 2011.

36. Bollinger L, Perham K, DeCormier Plosky W. Grading Goals: A Systematic Review of Studies in the Goals Model. Vienna: Paper presented at: Abstract no. WEPE0817; 2010.

37. World Health Organization (WHO). Guidelines for Conducting HIV Surveillance Among Pregnant Women Attending Antenatal Clinics Based on Routine Programme Data. Geneva: WHO; 2015.

38. The DHS program: Data. https://dhsprogram.com/data/availabledatasets.cfm. Accessed 2014.

39. UNAIDS. UNAIDS Data. http://www.unaids.org/en/resources/ documents/2017/2017_data_book.

40. Houben RM, Lalli M, Sumner T, et al. TIME Impact-a new user-friendly tuberculosis (TB) model to inform TB policy decisions. BMC Med. 2016;14:56. doi:10.1186/s12916-016-0608-4

41. World Health Organization (WHO). Systematic Screening for Active Tuberculosis: Principles and Recommendations. WHO; 2013.

42. Vassall A, van Kampen $\mathrm{S}$, Sohn $\mathrm{H}$, et al. Rapid diagnosis of tuberculosis with the Xpert MTB/RIF assay in high burden countries: a costeffectiveness analysis. PLoS Med. 2011;8(11):e1001120. doi:10.1371/ journal.pmed.1001120

43. van't Hoog AH, Langendam MW, Mitchell E, Sinclair D, Leeflang M, Lonnroth K. A Systematic Review of the Sensitivity and Specificity of Symptom and Chest Radiography Screening for Active Pulmonary Tuberculosis in HIV-Negative Persons and Persons with Unknown HIV Status. Geneva: WHO; 2013.

44. World Health Organization (WHO). WHO End TB Strategy: Globa strategy and targets for tuberculosis prevention, care and control after 2015. World Health Organization; 2015.

45. Stop TB Partnership. The Global Plan to End TB. Stop TB Partnership; 2015.

46. World Health Organization (WHO). Global Tuberculosis Report 2015. WHO; 2015.

47. World Health Organization (WHO). Publicly available TB database of the Global TB Program. http://www.who.int/tb/country/data/download/en/. Accessed 2014.

48. World Health Organization (WHO). Global Health Sector Strategy on HIV, 2016-2021. WHO; 2016 
49. World Health Organization (WHO). Consolidated Guidelines on HIV Prevention, Diagnosis, Treatment and Care for Key Populations. WHO; 2016.

50. World Health Organization (WHO). Consolidated Guidelines on the Use of Antiretroviral Drugs for Treating and Preventing HIV Infection: Recommendations for a Public Health Approach. WHO; 2016.

51. World Health Organization (WHO). Consolidated Guidelines on HIV Testing Services. WHO; 2015.

52. World Health Organization (WHO). Guidelines on HIV Self-Testing and Partner Notification. WHO; 2016.

53. World Health Organization (WHO). Implementing the End TB Strategy: The Essentials. WHO; 2015.

54. World Health Organization (WHO). Infection Prevention and Control of Epidemic-And Pandemic Prone Acute Respiratory Infections in Health Care. WHO; 2014

55. World Health Organization (WHO). Global Tuberculosis Report 2018. Geneva: WHO; 2018.

56. World Health Organization (WHO). Guidelines for the Treatment of DrugSusceptible Tuberculosis and Patient Care. WHO; 2017.

57. World Health Organization (WHO). A Guide to Monitoring and Evaluation for Collaborative TB/HIV Activities. WHO; 2015.

58. World Health Organization (WHO). Guidelines for Malaria Vector Control. WHO; 2019.

59. World Health Organization (WHO). Malaria: Intermittent Preventive Treatment in Pregnancy (IPTp). WHO; 2018.

60. World Health Organization (WHO). WHO Recommendations on Antenatal Care for A Positive Pregnancy Experience. Geneva: WHO; 2016.

61. World Health Organization (WHO). WHO Policy Recommendation on Intermittent Preventive Treatment During Infancy with SulphadoxinePyrimethamine (IPTi-SP) for Plasmodium Falciparum Malaria Control in Africa. WHO; 2010.
62. World Health Organization (WHO). WHO Policy Recommendation: Seasonal Malaria Chemoprevention (SMC) for Plasmodium Falciparum Malaria Control in Highly Seasonal Transmission Areas of the Sahel SubRegion in Africa. WHO; 2012.

63. World Health Organization (WHO). Guidelines for the Treatment of Malaria. 3rd ed. Geneva: WHO; 2015.

64. Bertram MY, Stenberg K, Brindley C, et al. Disease control programme support costs: an update of WHO-CHOICE methodology, price databases and quantity assumptions. Cost Eff Resour Alloc. 2017;15:21. doi:10.1186/ s12962-017-0083-6

65. World Health Organization (WHO). Immunization Costing \& Financing: A Tool and User Guide for Comprehensive Multi-Year Planning (cMYP). Geneva: WHO; 2006.

66. World Health Organization (WHO). Voluntary Medical Male Circumcision for HIV Prevention in 14 Priority Countries in East and Southern Africa: WHO Progress Brief. WHO; 2017.

67. Hankins C, Forsythe S, Njeuhmeli E. Voluntary medical male circumcision: an introduction to the cost, impact, and challenges of accelerated scaling up. PLoS Med. 2011;8(11):e1001127. doi:10.1371/journal.pmed.1001127

68. World Health Organization (WHO). Preparation for the third high-level meeting of the General Assembly on the prevention and control of noncommunicable diseases, to be held in 2018: Report by the DirectorGeneral. WHO; 2016.

69. World Health Assembly. Follow-Up to the Political Declaration of the HighLevel Meeting of the General Assembly on the Prevention and Control of Non-Communicable Diseases: Sixty-Fourth. Geneva: World Health Assembly; 2013.

70. Tan-Torres Edejer T, Baltussen R, Adam T, et al. Making Choices in Health: WHO Guide to Cost-effectiveness Analysis. Geneva: WHO; 2003. 